\title{
Laser in Orthodontics
}

\author{
Fekrazad Reza1, Kalhori A.M. Katayoun², \\ Ahrari Farzaneh ${ }^{3}$ and Tadayon Nikoo 4 \\ 1 Periodontist, Dental Department, AJA University of Medical Sciences, Laser Research \\ Centre of Dentistry, Tehran University of Medical Sciences, Tehran, \\ ${ }^{2}$ Oral \& Maxillofacial Pathologist, Laser Research Centre of Dentistry, \\ Tehran University of Medical Sciences, Tehran, \\ ${ }^{3}$ Orthodontist, Department of Orthodontics, \\ Mashhad University of Medical Sciences, Mashhad, \\ ${ }^{4}$ Pedodontist, Private Practice, Tehran, \\ Iran
}

\section{Introduction}

\subsection{Preface}

For many years research in Laser supported therapies in Dental Sciences is progressing steadily. There is no field of dentistry where development took place at such a tearing pace in recent years as in the field of laser dentistry. In the beginning it was only in some branches of this scientific field where significant therapeutic advantages compared to conventional forms of treatment could be reached, but by now this development already includes all branches of dentistry and integrates them into the spectrum of laser supported dental treatment. A great variety of different wavelengths always presents new possibilities of use with constantly new partly almost unbelievable -accomplishments. Everyone who wants to conduct conscientious dentistry in the future inevitably has to integrate the advantages of laser substitution into his or her therapeutic strategy.

\subsection{History}

Laser' is an acronym for 'light amplification by the stimulation emission of radiation'. Its theoretical basis was postulated by Albert Einstein. In explaining the photoelectric effect, Einstein assumed that a photon could penetrate matter, where it would collide with an atom. Since all atoms have electrons, an electron would be ejected from the atom by the energy of the photon, with great velocity. Einstein also predicted in 1917 in Zur Theorie der Strahlung (Theory of Wavelength), that when there exists the population inversion between the upper and lower energy levels among the atom systems, it was possible to realize amplified stimulated radiation, ie laser light. Stimulated electromagnetic radiation emission has the same frequency (wavelength) and phase (coherence) as the incident radiation. (Einstein, 1905, 1917)

The laser was demonstrated for the first time in 1960 by Maiman after the pioneering the oretical work of Basov, Prokhorov and Townes (Schawlow \&Townes, 1940, 1949, 1958, 1994) Many other kinds of laser were invented soon after the solid ruby laser - the first uranium 
laser by IBM Laboratories (in November 1960), the first helium-neon laser by Bell Laboratories in 1961 (Javan et al)and the first semiconductor laser by Robert Hall at General Electric Laboratories in 1962; the first working neodymium-doped yttrium aluminium garnet (Nd:YAG) laser and CO2 laser by Bell Laboratories in 1964, argon ion laser in 1964, chemical laser in 1965 and metal vapour laser in 1966. In each case, the 'name' of the laser was annotated with regard to the active medium (source of laser photons) used.

There is a specific and fundamental relationship between light wavelength and absorption by an 'illuminated' target material. Thus, the unique nature of laser light and its specific absorption, led to an expansion of its use in medicine. Within a year of the invention, pioneers such as Dr Leon Goldman began research on the interaction of laser light on biologic systems, including early clinical studies on humans (Goldman et al., 1964)

Although Maiman(1960) had exposed an extracted tooth to his ruby laser in 1960, the possibilities for laser use in dentistry did not occur until 1989, with the production of the American Dental Laser for commercial use. This laser, using an active medium of Nd:YAG, emitted pulsed light and was developed and marketed by Terry Myers(1989), an American dentist. Though low-powered and due to its emission wavelength, inappropriate for use on dental hard tissue, the availability of a dedicated laser for oral use gained popularity amongst dentists. This laser was first sold in the UK in 1990.In 1989, experimental work by Keller and Hibst (1989) using a pulsed Erbium YAG $(2,940 \mathrm{~nm})$ laser, demonstrated its effectiveness in cutting enamel, dentine and bone. This laser became commercially available in the UK in 1995 and, shortly followed by a similar Er,Cr:YSGG (erbium chromium: yttrium scandium gallium garnet) laser in 1997, amounted to a laser armamentarium that would address the surgical needs of clinical dentistry in general practice .

\subsection{Laser definition}

As explained before the word laser is an acronym for Light Amplification by Stimulated Emission of Radiation. The scientific rationale for the use of lasers in dentistry can be reviewed in that context. Light is a form of energy that travels in a wave and exists as a particle. ${ }^{1}$ this particle is called a photon.

Laser is an acronym which completely describes the whole physical process of the generation of light. The laser is in fact energy transformer. Different kinds of energy, such as light, kinetic of electrical energy, are transformed into a new kind of optical energy with special properties. This new kind of optical energy is completely artificial and cannot be found anywhere in nature. Based on this consideration, it can be stated that a laser transforms energy of "low quality" into a kind of energy which has "high quality" (Meister, 2007).Special materials with well defined properties must be used to transform the energy during the simultaneous generation of light. These materials can be gases, Liquids, Semiconductor materials, glasses or artificial gemstones (crystals), and moving charged particles. Therefore, the systems will be classified as gas, dye, semiconductor, solid-state and free-electron laser (Meister, 2007).

The component parts of a typical laser are:

\section{Active medium}

A material, either naturally occurring or man-made that when stimulated, emits laser light. This material may be a solid, liquid or gas. The first 'dental' laser used a crystal of neodymiumdoped yttrium Aluminium garnet (Nd:YAG) as its active medium. 'YAG' is a complex crystal with the chemical composition Y3A15O12. During crystal growth, $1 \%$ neodymium $(\mathrm{Nd} 3+)$ ions 
are doped into the YAG crystal (Parker,2007).The active medium is positioned within the laser cavity, an internally-polished tube, with mirrors co-axially positioned at each end and surrounded by the external energizing input, or pumping mechanism.

\section{Excitation Energy}

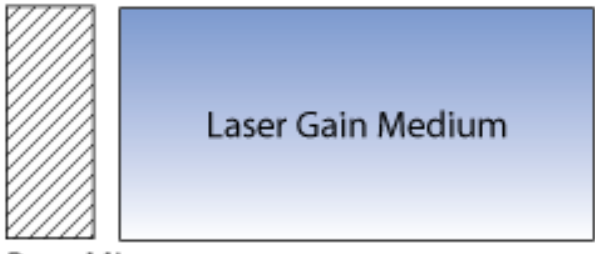

Rear Mirror

Total Reflector

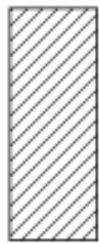

Front Mirror/Output Coupler Partial Reflector

Fig. 1. The component parts of a typical laser

\section{Pumping mechanism}

This represents a man-made source of primary energy that excites the active medium. This is usually a light source, either a flashlight or arc-light, but can be a diode laser unit or an electromagnetic coil. Energy from this primary source is absorbed by the active medium, resulting in the production of laser light. This process is very inefficient, with only some 3$10 \%$ of incident energy resulting in laser light, 9 the rest being converted to heat energy.

\section{Optical resonator}

Laser light produced by the stimulated active medium is bounced back and forth through the axis of the laser cavity, using two mirrors placed at either end, thus amplifying the power. The distal mirror is totally reflective and the proximal mirror is partly transmissive, so that at a given energy density, laser light will escape to be transmitted to the target tissue(Parker,2007). (Fig.1)

\subsection{Delivery system}

Dependant upon the emitted wavelength, the delivery system may be a quartz fiber-optic, a flexible hollow waveguide, an articulated arm (incorporating mirrors), or a hand-piece containing the laser unit (at present only for low-powered lasers). Early attempts to produce delivery systems relied upon the use of fixed mirror and/or lens apparatus. Therefore, shorter wavelengths such as argon, diodes and Nd:YAG can enjoy such fiber delivery, whereas longer wavelengths (Er,Cr:YSGG, Er:YAG and carbon dioxide) give rise to severe power losses through quartz fiber and hence require alternative delivery systems (Merberg,1993;Inberg et al.,1998;Konorov et al.,2004).

\subsection{Characteristics of laser light}

A wave of photons has 3 basic properties:

(1) A constant velocity (the speed of light).(2) Amplitude (the vertical measurement of the height of the wave, from top to bottom). This is a measurement of energy of that wave, expressed as a joule, or 1 unit of energy. In dental applications, a useful quantity is a mill joule, one thousandth of a joule.(3) Wavelength (the horizontal distance between any 2 corresponding points of the wave). 
Both ordinary light and laser light consist of waves. However, laser light is distinguished from ordinary light by the following 2 properties:(1) Laser light is generated as only 1 colour, a property called monochromaticism. This color can be either visible or invisible to the human eye, but is described as the measurement of the wavelength, which, for dental lasers, is expressed in nanometres (one billionth of a meter).(2) The waves of laser light are coherent for all lasers. Each wave is identical in physical size and shape. This monochromatic, coherent wave of light energy emerges from the laser device as a precise, collimated beam. These properties make the laser beam a uniquely efficient source of energy (Meserendino \& Pick, 1995).

\subsection{Model of operation}

Laser sources can emit light continuously or in pulsed fashion. The difference is related to the time -limited emission of such a system. In what is known As: continuous-wave" (CW) mode. Carbon dioxide, argon, and diode lasers operate in this manner.If the time - limited emission is less than $0.25 \mathrm{~s}$. the laser emits light in so-called "pulse" mode. Free-running pulse, which has very short bursts of laser energy, with each pulse being a few 10 thousandths of a second in duration. Nd and Er:YAG, as well as Er,Cr:YSGG devices operate as free-running pulsed lasers.A special case of pulsed laser operation is the chopped mode. A continuously emitting laser beam is interrupted at regular intervals using different kinds of apertures through which the light can pass. Compared to the regular pulse operation of a laser, the apertures are placed outside the Laser Set-up where the energy is transformed.

\subsection{Laser types in dentistry}

A wide variety of laser systems have been established in dentistry (Wigdor et al., 1995). The available radiation is emitted from the blue spectral range up to the mid-infrared region. Numerous different applications have been developed, depending on the varying parameters of the emitted laser light. It is important to know what kind of laser is suited to a specific indication, in order to get the maximum benefit by implementing this technology in dental practice (Meister, 2007).

\subsubsection{The argon ion laser}

Ionized gases and vapors represent only a small segment of the range of media suitable for use in lasers. The idea of using ionized noble gases as laser media was realized technically by Gordon et al. in 1964, i. e., again in the early years of laser development. Noble - gas ion lasers using argon, krypton and xenon are among the most powerful continuous-wave lasers in the visible range of the spectrum. Especially in dentistry, the Argon ion laser is used, for example, for soft-tissue surgery, photo-polymerization and decay prevention (Mattson et al. 1998, Powell et al. 1995, Anderson et al. 2002, Hicks et al. 2004).

Argon's strongest emission lines at $488 \mathrm{~nm}$ and $514.5 \mathrm{~nm}$ are of relevance for dental applications. The $488 \mathrm{~nm}$ line and lines beneath are used for photo- polymerization caused by absorption in campherchinone, and the $488 / 514.5 \mathrm{~nm}$ combination is suitable for softtissue surgery due to the high absorption in melanin, hemoglobin and oxyhemoglobin.

\subsubsection{The helium - neon laser}

The Helium- neon laser was not only the first gas laser, but also the first continuous-wave laser in the history of laser development (Javan et al. 1961). It is the typical representative of 
the class of neutral- gas atomic lasers.Thanks to its visible emission line at $623.8 \mathrm{~nm}$ and owing to its outstanding optical properties; this laser is commonly used as a tool for adjusting optical and mechanical systems, in holography and interfermetry, as well as in applications in biology and medicine. Its in expensive production also contributes to the worldwide use of this laser. It is thus not surprising that a laser of this kind operating at the above wavelength was also the first to be used in photodynamic therapy (Dougherty 1993) and low - level laser therapy (Saperia et al. 1986, Gomi et al. 1986, Bihari \& Mester 1989).He$\mathrm{Ne}$ lasers operating with various wave-lengths in single-line and multi-line dome are available commercially. Their emission range extends from intermediate and near infrared $(3391,1523,1152, \mathrm{~nm})$, red $(640,635,632.8,629 \mathrm{~nm})$, orange $(612,604 \mathrm{~nm})$ and yellow $(594$ $\mathrm{nm})$ all the way to the green $(543 \mathrm{~nm})$ spectral range. The output power of these systems varies between $<1 \mathrm{~mW}$ to several $10 \mathrm{Mw}(3391 \mathrm{~nm}$ and $632.9 \mathrm{~nm})$ the power generally being increased exclusively by extending the amplification path.

\subsubsection{The semiconductor laser}

Laser activity in semiconductor crystal was first observed in 1962 (Hall et al., Nathan et al., Holonyak et al., Quist et al.). So-called semiconductor or diode lasers emit coherent radiation in the ultraviolet (UV), visible(VIS) and infrared (IR) spectral ranges. The first semiconductor lasers were pulsed and operated at low temperatures. Not until 1970 was continuous - wave operation at room temperature achieved. Suitable semiconductor compounds are the elements of Groups II to VI the periodic table. They primarily include gallium -arsenide (GaAS) compounds, with mixed crystals including elements from Groups III to $\mathrm{V}$ being of particular importance. Diode lasers that are based on the elements gallium and arsenic and arsenic and emit in the range of 700-1,000 nm, i.e., in the near IR region of the spectrum, have become increasingly important in recent years. Especially in dentistry, 810 and $980 \mathrm{~nm}$ had become the most important wavelengths for using these lasers in endodontics and periodontics (Kimura et al. 2000, Aoki et al. 2004).

\subsubsection{The neodymium: YAG laser}

The Neodymium: YAG laser was developed in 1964 (Geusic et al. 1964) and is the classical and most widely used solid- state laser. Emitting its strongest fundamental wave length at $1,064 \mathrm{~nm}$, the Neodymium : YAG laser is characterized by a relatively simple set - up and the generation of high output powers, both in pulsed mode at high repetition rates (up to 10 $\mathrm{kHz}$ ) and in continuous wave mode (Geusic 1966). The actual laser process takes place in the neodymium ion $\left(\mathrm{Nd}^{3+}\right)$. Neodymium belongs to the group of rare earths (lanthanides) and is embedded in a host crystal consisting of Yttrium - Aluminium -Garnet (YAG, $\mathrm{Y}_{3} \mathrm{~A}_{15} \mathrm{O}_{12}$ ).

\subsubsection{The erbium family lasers}

Since 1988 Erbium lasers are the mainly used laser systems in dentistry for cavity preparation (Paghdiwala 1988, Hibst et al. 1089, Keller 1989). Their emission wavelengths are in the spectral range from 2.6 to $3 \mu \mathrm{m}$ and are perfectly matched to the absorption maximum of water and the $\mathrm{OH}$ - groups, also found as components of dental tissue. Two Erbium laser systems are preferred dentistry: first, the Erbium: YAG laser, which emits light at $2.94 \mu \mathrm{m}$ (Zharikov et al. 1975), and second, the Erbium, chromium: YSGG laser, which emits light at $2.79 \mu \mathrm{m}$ (Zharikov et al. 1984, Moulton et al. 1988).In general, Erbium lasers are excited by flash lamps. This implies that these lasers cannot run in continuous-wave mode due to the 
long lifetime of the lower laser level. In pulsed mode, however, Erbium lasers can be operated up to a pulse repetition rate of $40 \mathrm{~Hz}$ and average powers of $20 \mathrm{~W}$ at pulse energies of $1 \mathrm{~J}$.

\subsubsection{The carbon dioxide laser}

The Carbon dioxide laser is the most powerful gas laser. Its technical realization was achieved by Patel in 1964 (1964 a,b) .In dentistry , use is generally made of low power sealed tubes with CW output powers of up to $50 \mathrm{~W}$ and pulsed - mode outputs of up to $300 \mathrm{~W}$. The transformer or active medium of a Carbon dioxide laser is a mixture of Carbon dioxide (laser gas), nitrogen (excitation gas) and helium (cooling gas). The preferred laser transitions occur at 9.6 and $10.6 \mu \mathrm{m}$, with the emission at $10.6 \mu \mathrm{m}$ describing the strongest laser transition. The Carbon dioxide laser is used for a variety of purposes in dentistry. Its strong absorption in water and hydroxyl apatite (maximum at $9.6 \mu \mathrm{m}$ ) makes it an ideal instrument for surgery on soft and hard tissue.

\subsection{Light - Tissue interaction}

When electromagnetic radiation hits biological tissue, different interactions occur as a function of various physical parameters. The processes occurring during the propagation of light in so- called turbid media can be divided into three cases (Hall and Girkin 2004):

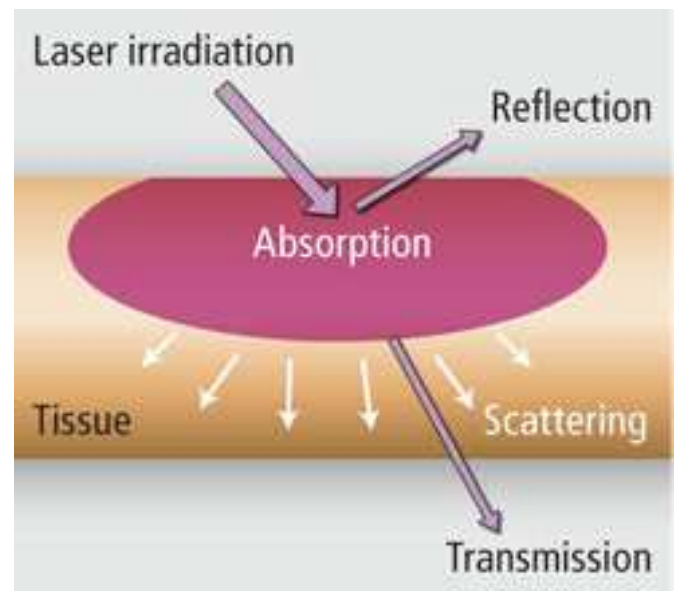

Fig. 2. What happens when Laser hits the tissue?

- Reflections on the tissue surface Reflection is a surface phenomenon (Fresnel reflection), resulting in the change in direction of the light wave caused by single interaction with a large object, the direction of the reflected wave often being opposite the incident wave. In reflection, wavelength or photon energy of the light wave is not altered.(Fig.2)

- Interactions in the tissue

\section{Absorption}

The energy of the light is absorbed by the object and then converted into a different form such as heat, for instance. An object can also absorb the energy of the light and then reemit this energy as another light which has less energy. This process is well known as florescence. (Fig.3) 


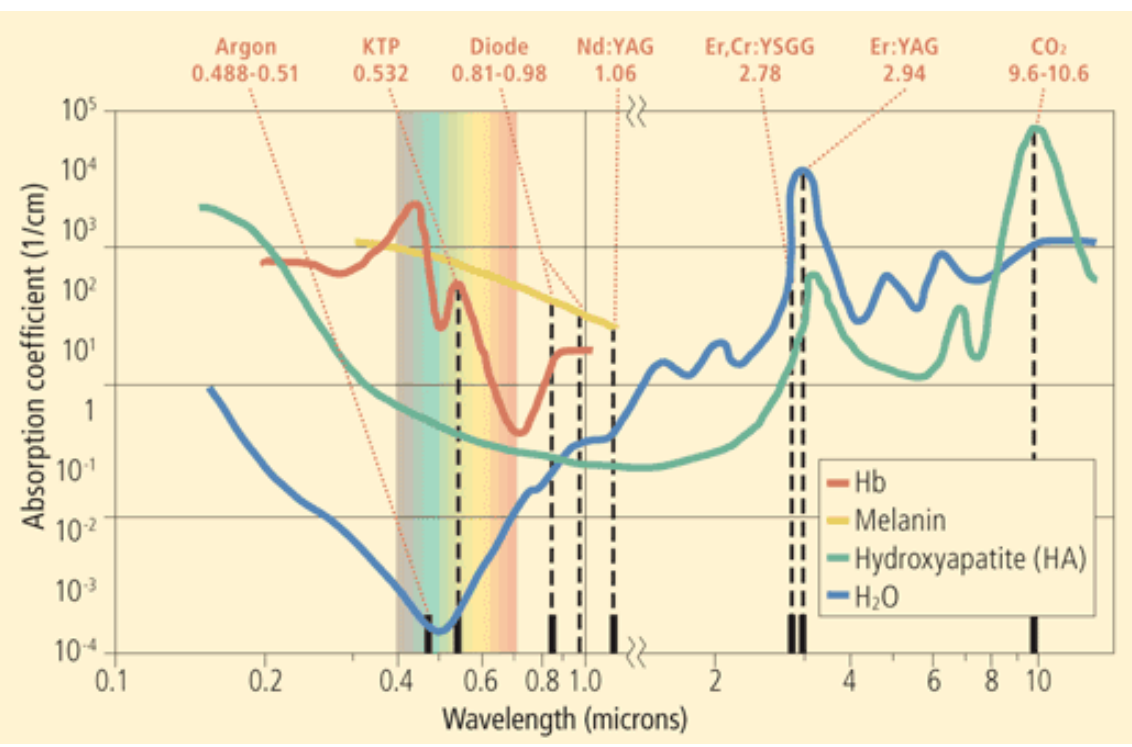

Fig. 3. Absorption curve of various tissue components.

\section{Scattering}

Scattering is the change in direction of a light wave on single or multiple occasions when it interacts with a small particle or object within inhomogeneous and/or turbid materials. The scattering of a light wave with the objects may, or may not, cause a change in the energy of the incident light wave, resulting in absorption, diffuse reflection or diffuse transmission. The angle or quantity of scattering depends on the relative sizes of the wavelength and the particles.

- Penetration of the tissue

- The wave is not influenced by the material. The energy and direction of propagation of the wave of incident is not changed during transmission. The light is transmitted as a collimated beam (Meister, 2007).

In short, laser-tissue interactions depend on the interplay of irradiation parameters: 1) wavelength or wavelength band of that particular laser source; 2) physical properties of the tissue irradiated with that particular wavelength or wavelength band; 3) irradiance or pulse energy; 4) continuous wave (CW) or pulsed irradiation; 5$)$ laser beam size on the tissue; 6 ) irradiation duration or laser pulse length and repetition rate; and 7) any change in the physical properties of the tissue as a result of laser irradiation with the parameters (3-6) above( Cilesiz,2004). At low irradiances and/or energies, laser-tissue interactions are either purely optical or a combination of optical and photochemical or photobiostimulative. When laser power or pulse energy is increased, photothermal interactions start dominating. Finally, photomechanical (sometimes referred to as photoacoustic) effects become apparent when repetitive and very short laser pulses are delivered to the tissue. Therefore there are five interaction mechanisms associated with the use of lasers in biomedicine: 1) purely optical, e.g., fluorescence spectroscopy for cancer screening, optical coherence tomography (OCT) for high-resolution imaging; 2) photochemical (causes target cells to start lightinduced chemical reactions.), e.g., photodynamic therapy (PDT); photobiostimulative, e.g., 
laser acupuncture;3) Photoablative,(causes photodissociation or breaking of the molecular bonds in tissue.) 4) photothermal(converts light energy into heat energy. This causes the tissue to heat up and vaporize.), e.g., laser-assisted refraction correction by ablation of parts of cornea, tattoo removal; and 5) photomechanical (photoacoustic),( causes dielectric breakdown in tissue caused by shock wave plasma expansion resulting in localized mechanical rupture.) e.g., laser lithotripsy.

A comparative plot of laser-tissue interactions as a function of exposure time and irradiance is given in Fig. 4. Niemz (2002) emphasizes that all laser-tissue interaction mechanisms share a common datum: characteristic energy density varies typically between 1 and $1000 \mathrm{~J} / \mathrm{cm}^{2}$, whereas irradiance varies over 15 orders of magnitude. Consequently, laser exposure duration is the parameter that determines the nature of laser-tissue interactions. (Cilesiz, 2004)

Niemz (2002) has also determined that all effects with near-infrared laser wavelengths at pulse durations of 1 microsecond or greater are thermal in nature. There are 5 factors to consider regarding heat generation by these lasers:(1) wavelength and optical penetration depth of the laser;(2) absorption characteristics of exposed tissue;(3) temporal mode (pulsed or continuous);(4) exposure time; and(5) power density of the laser beam.

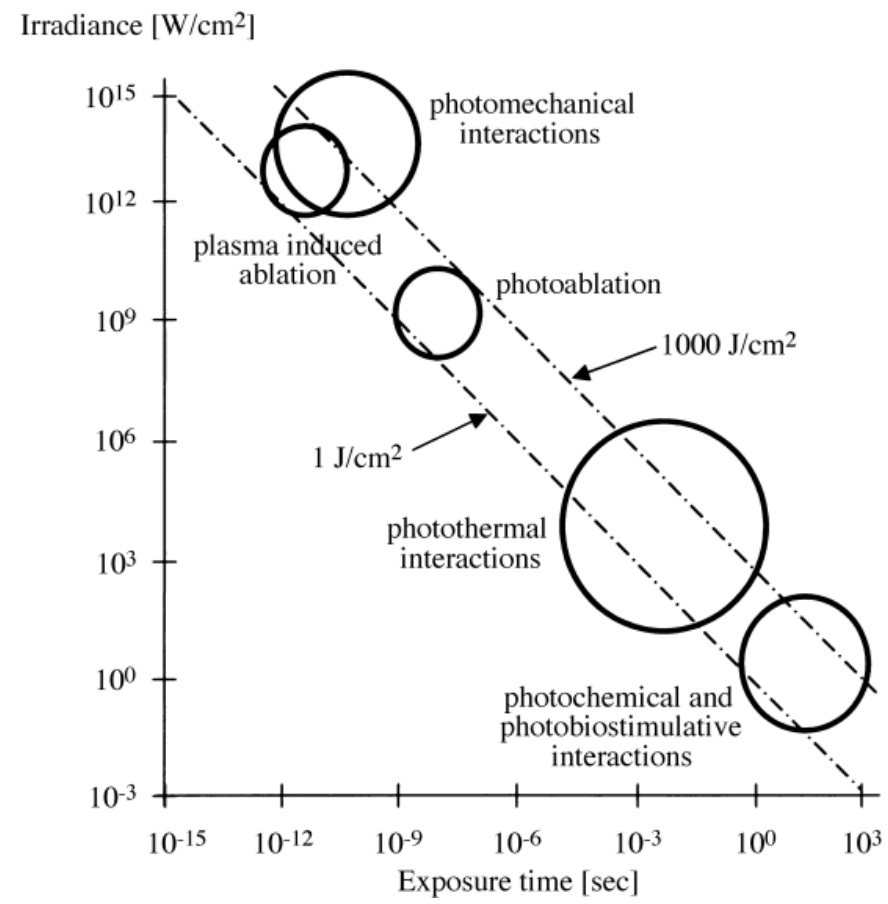

Fig. 4. Representation of laser-tissue interactions in terms of exposure time and irradiance

\section{Diagnostic lasers}

\subsubsection{Tree-dimensional laser scanning and reconstruction (holography)}

Three-dimensional (3D) laser scanners are increasingly being used in orthodontics to establish databases for normative populations (Yamada et al. 2002) and cross sectional 
growth changes (Nute and Moss 2000), and also to assess clinical outcomes in orthognathic surgical (McCance et al. 1992, Ayoub et al. 1996, McCance et al. 1997, Ayoub et al. 1998, Ji et al. 2002, Khambay et al. 2002, Marmulla et al. 2003) and nonsurgical treatments (McDonagh et al. 2001, Ismail et al. 2002, Moss et al. 2003, Jang et al. 2009).

The basic concepts of the system have been described by Arridge et al (1985). The laser system consisted of two vertically fanned out low power helium-neon laser beams which were projected on to the face and viewed from an oblique angle by a television camera. In 1988 Ayoub et al. (1996) developed a video-capture stereoscopic method of imaging. Two pairs of stereo cameras ensured that the curved facial surfaces were completely imaged within 2 seconds. The system allowed photo-realistic image generation of the face that could be viewed from any direction. This polygonal facial model could be used to measure facial landmarks and volumes. Various applications of laser holography in orthodontics are:

\subsubsection{Facial soft tissue analysis}

The recent emphases on soft tissues as the limiting factor in treatment and on soft-tissue relationships in establishing the goals of treatment has made 3D analysis of soft tissues more important in diagnosis and treatment planning. It is equally important to be able to detect changes in the facial soft tissues produced by growth or treatment. With advancement in technology, laser-scanning devices are now smaller and can be assembled in any location for studies on facial morphology (Kau et al. 2004). The scanning process is non-invasive and normally completed within a few seconds. Furthermore, the data acquired is accurate to approximately $0.5 \mathrm{~mm}$, depending on the technique used (Arridge et al., 1985; Moss et al., 1987, 1988, 2003; Nute and Moss 2000; Kau et al., 2005). These systems are valuable tools for their ease of application and creation of 3D images. It has been stated that there are many advantages of laser scanners over other types of 3D imaging technology in terms of cost, speed, and portability (Sholts et al. 2010).

\subsubsection{Digital models}

Orthodontic study models are usually collected by clinicians to aid diagnosis, monitor treatment, and complement the written record. Study models are also used in research, audit, and teaching. The need to retain dental casts for future reference has created storage problems for orthodontists (McGuinness and Stephens, 1992). The holograms offer a more convenient and cost-effective means of recording and maintaining this information accurately. These computer-based digital orthodontic models have the potential for assessing tooth size, arch form, and tooth-arch discrepancies (Alcaniz et al., 1999; Lu et al., 2000; Hirogaki et al., 2001; Santoro et al., 2003; Quimby et al., 2004). Some investigators have performed 3D superimposition of dental casts to analyze orthodontic tooth movement (Ashmore et al. 2002, Hayashi et al. 2002, Hayashi et al.2004, Yao et al. 2005, Cha et al. 2007). It has been claimed that most parameters on the digital models can be reliably measured, and digital models can potentially eliminate the requirement for the production and storage of dental casts (Asquith et al. 2007). In recent times the cost limitation of laser linear scanning has been addressed by high throughput commercial production.

\subsection{Laser Doppler flowmetry}

The laser Doppler flowmetry (LDF), developed in the 1970s as a noninvasive electro-optical technique to measure the velocity of red cells in skin capillaries, has been used for the 
diagnosis of pulp vitality in human teeth (Gazelius et al. 1986). The original technique utilized a light beam from a helium-neon (He-Ne) laser emitting at $632.8 \mathrm{~nm}$, which, when scattered by moving red cells underwent a frequency shift according to the Doppler principle. A fraction of the light back-scattered from the illuminated area, shifted frequency in this way. This light was detected and processed to produce a signal that was a function of the red cell flux. This information was used as a measure of blood flow, the value being expressed as a percentage of full-scale deflection at a given gain. Other wavelengths of semiconductor laser have also been used: $780 \mathrm{~nm}$ and 780-820 nm (Kimura et al. 2000). Zang et al. (1996) demonstrated greatly improved results using forward scattering detection as opposed to conventional backward scattering detection. These results were confirmed by Sasano (1998). Odor et al. (1996) reported that the $810 \mathrm{~nm}$ wavelength showed good sensitivity but poor specificity and that the $633 \mathrm{~nm}$ wavelength showed good specificity but poor sensitivity. In general, infrared light $(780-810 \mathrm{~nm})$ has a greater ability to penetrate enamel and dentine than shorter wavelength red light $(632.8 \mathrm{~nm})$ (Vongsavan et al. 1993). The lasers used for LDF are usually at a low-power level of 1 or $2 \mathrm{~mW}$ and no reports on pulp injury by this method have been made. Konno et al. (2007) stated that high-powered (5 $\mathrm{mW}$ ) transmitted laser light could be a better tool for both monitoring the pulpal blood flow of the teeth and assessing tooth-pulp vitality than the conventional back-scattered light flow meter apparatus. It was suggested that this was due to because blood-flow signals did not include flow of nonpulpal origin, and also because the output signals and responses to blood-flow changes were clear and could easily be monitored.

LDF techniques are united in their validity for pulp vitality testing as they reflect vascular rather than nervous responsiveness (Tronstad 1992). Pulpal responses to orthodontic forces or the orthopedic forces created by rapid maxillary expansion have previously been investigated by LDF (McDonald et al. 1994, Barwick \& Ramsay 1996, Brodin et al. 1996, Ikawa et al. 2001, Sano et al. 2002, Konno et al. 2007, Babacan et al. 2010). LDF is also a reliable method for blood flow measurements after orthognathic surgery. Among patients who undergo a segmental maxillary osteotomy or Le fort I osteotomy, significant reduction in pulpal sensibility has been noted in teeth in the osteotomized segment or maxilla (Yoshida et al. 1996, Firestone et al. 1997, Harada et al. 2004, Emshoff et al. 2000, Emshoff et al. 2008).

\subsection{Laser florescence for caries detection}

The early detection and quantification of initial caries formed around orthodontic brackets is a possibility aiming to minimize the damage of caries lesions in orthodontic patients (Aljehani et al. 2004, Staudt et al. 2004). Quantitative methods would be able to detect caries lesions earlier than visual inspection would, and such methods could be used to assess the outcome of preventive interventions (Alencar et al. 2009).

The laser fluorescence (LF) device is a quantitative method based on emission of light from a diode laser at a wavelength of $655 \mathrm{~nm}$ and measurement of the fluorescence emitted mainly from the carious tissues. At this wavelength, clean healthy teeth exhibit little or no fluorescence. In contrast, demineralized teeth exhibit fluorescence proportionate to the degree of demineralization, resulting in elevated scale readings on the display. The fluorescence is believed to originate from protoporphyrin IX and related metabolic products of oral bacteria (Konig et al.1998, Lussi et al. 2004, Gostanian et al. 2006). The LF device may be useful for assessing the severity, progression, and depth of white spot lesions during orthodontic treatment (Benham et al. 2009). 
Two versions of the LF device are currently available commercially. The older version (DIAGNOdent, Kavo, Biberach, Germany) which was introduced in 1998, is used to detect occlusal and smooth surface caries. The latest version, the DIAGNOdent pen (LFpen) (Kavo), has been designed for easier access to a proximal surfaces (Lussi et al. 2006).

The original LF device has shown good performance and reproducibility for detection and quantification of occlusal and smooth surface caries lesions in in-vitro studies, but the results of in-vivo studies have been somewhat contradictory (Rocha et al. 2003, Anttonen et al. 2004, Astvaldsdottir et al. 2004, Tranaeus et al. 2004, Bamzahim et al. 2005, Angnes et al. 2005, Akarsu and Koprulu 2006, Reis et al. 2006, Abalos et al. 2009, Chu et al. 2009, Khalife et al. 2009). A review by Bader and Shugars (2004) disclosed that although several evaluations of diagnostic performance have appeared in the literature, the range of the LF device performances is extensive. For detection of dentinal caries, sensitivity values ranged widely ( 0.19 to 1.0 ) although most tended to be high. Specificity values exhibited a similar pattern, ranging from 0.52 to 1.0. In comparison with visual assessment methods, the LF exhibited a sensitivity value that was almost always higher and a specificity value that was almost always lower. The LF pen has performed as well as the original device on occlusal surfaces in vitro (Lussi et al. 2006). To date, there is only one published study of the clinical performance of the LF pen on occlusal surfaces (Huth et al. 2008).

In general, in vivo studies of LF for occlusal caries detection indicate moderate to high sensitivity and lower specificity (Bader and Shugars 2004, Reis et al. 2006, Abalos et al. 2009, Chu et al. 2009). Therefore, the LF device should be regarded at most as a supplementary aid for detection of caries on coronal surfaces. Recently Alencar et al. (2009) proposed a new approach using the LF devices associated with fluorescent dyes and concluded these devices might be feasible options to be used in clinical association with porphyrins, in order to detect early demineralization around orthodontic brackets which cannot be estimated directly in a clinical situation.

\section{High intensity laser therapy in orthodontics}

\subsubsection{Laser curing of light-cured materials}

The application of visible light is necessary for initiating the polymerization reaction of many cements used in orthodontics, including photo-polymerized adhesive resins and some glass ionomer products. Camphorquinone, a photo initiator used in most dental adhesives, activates at wavelengths between 460 and $480 \mathrm{~nm}$ (blue region of the visible light spectrum), with a peak at $468 \mathrm{~nm}$ (Usumez et al., 2003). It has been demonstrated that at least 300 $\mathrm{mW} / \mathrm{cm} 2$ of light intensity is required for optimal curing of a 2-mm thick layer of resin composite (Rueggeberg et al., 1994). There are several options for curing of orthodontic cements:

\subsubsection{Conventional and fast quartz-tungsten-halogen (QTH) lights}

Halogen bulbs use electric energy to heat a quartz-halogen or tungsten-halogen filament to high temperatures. This filament then glows and creates light. In a halogen bulb, only $1 \%$ of electric energy is consumed for generation of light, and the rest is converted to heat, degrading the components of the bulb over time. Lifetime of halogen devices is less than 100 hours, and these are very sensitive to shock and vibration. The light produced by halogen devices has a wide wavelength range, including both ultraviolet and visible lights, necessitating the use of special filters to select blue light for emission. The light intensity of halogen lights may vary between $400 \mathrm{~mW} / \mathrm{cm} 2$ to $800 \mathrm{~mW} / \mathrm{cm} 2$. However, the output 
power of halogen bulbs is decreased over time, so that many halogen bulbs used in dental offices may have light intensities lower than what is considered optimal for sufficient polymerization of adhesives (Barghi et al., 1994). Curing time of 20 to 40 seconds is recommended when using conventional halogen lights for curing orthodontic adhesives and light-cured resin-modified glass ionomers, respectively (Cacciafesta et al., 2005). This may appear a time-consuming procedure for many clinicians, and therefore several attempts have been made to reduce the curing time by using devices that produce higher light intensities.

Fast halogen lamps have similar construction to conventional bulbs but they produce higher output intensities, exceeding $1000 \mathrm{~mW} / \mathrm{cm} 2$. This is achieved by using higher-output lamps or application of special light guides that focus the light and concentrate it onto a smaller beam area. This way, curing times can be reduced to half of the time needed for curing with conventional halogen lights. However, limitations of filter technique and thermal problems prevent from further development in halogen devices.

\subsubsection{Light emitting diodes (LEDs)}

In 1995, Mills (1995) introduced solid-state light-emitting diode (LED) technology to overcome the shortcomings of halogen bulbs in polymerization of light-cured materials. When an electric current flows through junctions of semiconductors, light is generated with little energy loss as heat. LEDs have a lifetime of over 10.000 hours, and show little degradation of output power over time. They require no filters to produce blue light, consume low power for operation and are small, cordless, and resistant to hock and vibration. The curing time of 20 to 40 seconds is recommended when using LED devices for polymerization of orthodontic cements. Several studies indicated that at similar irradiation times, LED units have comparable (Dunn and Taloumis, 2002; Silta et al., 2005; Bishara et al., 2003) or higher (Carvalho Fde et al., 2010) efficiency than conventional halogen devices in polymerization of orthodontic adhesives.

\subsubsection{Plasma arc units}

Xenon plasma arc lamps were introduced to provide high intensity curing of adhesive materials in dentistry. The device consisted of an anode and a cathode, placed in a quartz tube which fills with xenon gas. When an electron current is passed through xenon, the gas becomes ionized (plasma condition) and generates an intense white light, which should be filtered to deliver blue wavelengths. However, the frequency bands produced by plasma arc units are much narrower than those of halogen lights and therefore less filtering is required. The process of plasma light generation requires a high voltage and generates considerable heat. The lifespan of plasma discharged tubes is several hundred hours. The light intensity is between 1400 to $2400 \mathrm{~mW} / \mathrm{cm} 2$, (Wendl and Droschl, 2004) therefore less time is needed for polymerization of cements. According to manufacturer claims, 1 to 3 seconds of irradiation with plasma arc unit is sufficient for polymerization of most dental adhesives. However, Ip and Rock (2004) reported that irradiation time of 2 seconds with plasma light resulted in significantly lower bond strength than 20 seconds of curing with conventional halogen light. It seems that at least 4 to 10 seconds of plasma irradiation should be performed to achieve comparable bond strengths to conventional halogen bulbs.

\subsubsection{Argon laser}

Argon laser is promising for the polymerization of dental restorative materials because one of the argon laser's emission peaks $(488 \mathrm{~nm})$ matches well with the absorption peak of the 
photoinitiator, camphorquinone (CQ) in light-curing dental restorative materials. It was claimed that the argon laser can polymerize a light-cured orthodontic adhesive 4 times faster with the same or even higher bond strength (Talbot et al 2000) and with less frequency of enamel fracture at debonding than with the conventional curing light (Lalani et al. 2000). In addition, at recommended curing times, in-vitro pulp chamber temperature increases from the laser units were significantly lower than those of the conventional curing light (Powell et al. 1999). Therefore, the argon laser should not pose a serious thermal risk to the pulp if used at the recommended energies (Cobb et al. 2000, Anic et al. 1996).

James et al (2003) presented in-vitro mean shear bond strength results using adhesiveprecoated (APC) brackets for the argon laser $(238.1 \mathrm{~mW} / \mathrm{cm} 2,10$ seconds) of $4.2 \mathrm{MPa}$ compared with the conventional curing light $(771.9 \mathrm{~mW} / \mathrm{cm} 2,20$ seconds) of $5.3 \mathrm{MPa}$. Using a higher intensity argon laser (approximately $800 \mathrm{~mW} / \mathrm{cm} 2,10$ seconds) system, Lalani et al (2000) reported similar bond strengths with their conventional curing light (approximately $400 \mathrm{~mW} / \mathrm{cm} 2,40$ seconds) group.

Kelsey et al (1989) conducted a carefully controlled laboratory study to determine the optimum power setting and polymerization cycle time to cure 4 commercially available composite resins with an argon laser. The most effective resin polymerization was achieved when Prisma APH was polymerized $(310 \mathrm{~mW})$ for 7 seconds, when Herculite was polymerized $(160 \mathrm{~mW})$ for 12 seconds, when P-50 was polymerized $(525 \mathrm{~mW})$ for 13 seconds, and when Silux Plus was polymerized $(270 \mathrm{~mW})$ for 13 seconds. The authors concluded that the exact parameters of laser power and exposure time seem to be material specific, with greater variation noted in power settings than in exposure times. Talbot et al (2000) saw a significant difference between bond strength values at 3 laser energies (200, 230 , and $300 \mathrm{~mW}$ ). Therefore, it seems that the power setting is a major factor in the outcome of bond strength values.

Elvebak et al. (2006) tested the effects of curing time and light intensity on the shear bond strength of adhesive composites for stainless-steel orthodontic brackets. An argon laser at four different power settings $(100,150,200$, and $250 \mathrm{~mW})$ and four different exposure times $(5,10,15$, and 20 seconds) was used to bond APC stainless-steel brackets. They results showed the location of bond failure did not differ significantly in relation to exposure time. However, the location of bond failure was significantly different in relation to light power. They concluded that short exposure time and a low power setting produce shear bond strengths equivalent to those produced by longer exposure times and higher power settings. To date, little has been reported on the clinical performance of argon laser for orthodontic bracket bonding. Elaut and Wehrbein (2004) completed a 14-month prospective controlled clinical trial to assess the bond failure rate and decalcification incidence with conventional curing light and argon laser curing. There was no significant difference between curing methods for decalcification, but there were statistically fewer bond failures with the argon laser. They concluded that the clinical bond strength was superior with argon laser. Hildebrand et al. (2007) compared bond strengths after curing with the argon laser (10 seconds) and the conventional curing light (40 seconds) in vivo and in vitro. They stated that the bond strength for argon laser curing is comparable to conventional light curing and is sufficient for clinical applications. Although the argon laser left more adhesive on the tooth surfaces on debonding, there was no increase in enamel surface fractures.

Although the usefulness of argon lasers has been well documented, the expense of this laser has prevented it from becoming a popular light-curing source. Recently, Kim et al. (2010) assessed the effectiveness of the diode-pumped solid-state (DPSS) laser with a wavelength 
of $473 \mathrm{~nm}$ on the bonding of orthodontic brackets to teeth. This recently developed laser is expected to show similar features to the argon laser due to the similar emission wavelength. Furthermore, since this DPSS laser is compact and much cheaper than the argon laser, it has potential applications in dentistry instead of the argon laser. They concluded that the shear bond strength value of the DPSS laser-treated groups was similar to that of the control group (QTH light) and curing with DPSS laser will reduce chair time. However, future experiment is needed to support their claim.

\subsection{Enamel conditioning for bracket bonding with laser}

Proper conditioning of enamel surface is necessary for bonding of orthodontic attachments to teeth. In orthodontics, as in other fields of dentistry, the most common method of enamel preparation is acid phosphoric etching. Acid etching process prepares the surface by selective removal of interprismatic mineral structure, while the organic materials are less affected. The resultant rough and microfissured surface is very useful for retention of adhesive resins, but these structures are also more vulnerable to caries formation. Acid etching removes and demineralizes the most superficial and protective layer of enamel and makes the teeth more susceptible to long-term acid attack, especially when resin monomers can not sufficiently fill the demineralized area due to saliva contamination or air bubbles (Martinez-Insua et al., 2000). Since the prevalence of white spot lesions is very high among orthodontic patients (Gorelick et al., 1982), prevention of enamel demineralization is of great importance in orthodontics.

There has been extensive research to find an alternative conditioning method to overcome the main disadvantage of phosphoric acid etching, i.e. the potential for producing decalcification. Some researchers have worked on conditioning enamel with polyacrylic acid (Maijer and Smith, 1979) or pretreatment the enamel surface with sandblast of aluminum oxide (Canay et al., 2000) to reduce the rate of enamel loss during etching. However, these methods failed to achieve adequate bond strength to resist intraoral forces.(Canay et al. 2000; Jones et al., 1999)

Laser etching has become an alternative to acid etching of enamel. Laser etching is painless and does not involve either vibration or heat; also, the easy handling of the apparatus makes this treatment highly attractive for routine clinical use (Ozer et al. 2008). Laser etching of enamel creates microcracks that are ideal for resin penetration (Visuri et al. 1996). The surface produced by laser irradiation is also acid resistant. Laser irradiation of the enamel modifies the calcium-phosphate ratio and leads to the formation of more stable and less acid soluble compounds, thus reducing the susceptibility to caries attack (Oho et al. 1990, Klein et al. 2005). Because water spraying and air drying are not needed with laser etching, time can be saved (Usümez et al. 2002, Lee et al. 2003). From a clinical standpoint, saving chair time also improves adhesion because it reduces the risk of salivary contamination.

Different types of laser such as CO2, Er:YAG, Nd:YAG, and Er,Cr:YSGG have been used in orthodontics for enamel conditioning to bond brackets. Kim et al. (2005) and Lee et al. (2003) tested the effectiveness of Er:YAG laser in etching the enamel surface for orthodontic treatment and concluded that Er:YAG laser ablation can be an alternative tool to conventional acid etching.

Fuhrmann et al. (2001) concluded that CO2 and Nd:YAG dental lasers produce enamel conditioning and tensile bond strength sufficient to meet the requirements of bracket bonding. They stated that $\mathrm{CO} 2$ laser produces craters of various dimensions, while the 
Nd:YAG laser produces honeycomb structures regionally similar to enamel samples from the acid-etch technique. However, Ariyaratnam et al. (1997) believed that the Nd:YAG laser, when compared to $37 \%$ phosphoric acid, produces lower bond strength and alters the surface morphology of enamel. In another study, the authors claimed that dentinal surface exposed by the Nd:YAG laser exhibited microcracks and fissures, and concluded that this is not a suitable method for substituting dentinal acid etching (Ariyaratnam et al. 1999).

Ozer et al. (2008) compared Er,Cr:YSGG laser irradiation at 0.75 and $1.5 \mathrm{~W}$ with phosphoric acid etching and self etching primer for orthodontic bonding. They stated that varying power outputs of laser irradiation make different etching patterns: 0.75-W laser irradiation had lower shear bond strength, whereas 1.5-W power output showed comparable shear bond strengths with phosphoric acid and self etching primer. Basaran et al. (2007) reported that the mean shear bond strength and enamel surface etching obtained with an Er,Cr:YSGG laser (operated at $1 \mathrm{~W}$ or $2 \mathrm{~W}$ for 15 seconds) is comparable to that obtained with acid etching. Enamel and dentin surfaces etched with Er,Cr:YSGG lasers show microirregularities and no smear layer (Hossain et al. 1999). More recently Usümez et al.(2002) found that the results of enamel conditioning with Er,Cr:YSGG laser at $2 \mathrm{~W}$ of power $(20 \mathrm{~Hz}, 100 \mathrm{~mJ})$ were similar to those of acid etching. Cutting the power in half $(20 \mathrm{~Hz}$, $50 \mathrm{~mJ})$ significantly decreased the bond strength of the irradiated surface compared to acid etching; however, individual results varied greatly in each case. So they suggested that Er,Cr:YSGG laser by itself cannot be counted as a successful alternative to conventional methods of increasing bond strengths to enamel. This was recently confirmed by Jaberi ansari et al. (2011,in press) who claimed that re-etching with acid phosphoric will be necessary if Er,Cr:YSGG laser is used for tooth preparation or surface treatment.

Although there are some contradicting findings about the use of lasers for enamel etching, this may be due to the different outputs and experimental designs of the studies (Ozer et al. 2008).

\subsection{Bonding to porcelain}

Sometimes orthodontic attachments should be bonded to porcelain surfaces, a phenomenon which is most commonly seen in adult patients. Conventional acid etching is unable to produce sufficient bond strength of orthodontic brackets to porcelain surfaces. It has been demonstrated that the application of $9.6 \%$ hydrofluoric acid for 2 minutes provides suitable surface alterations for orthodontic bonding. (Zachrisson and Buyukyilmaz, 2005) However, the use of hydrofluoric acid can damage the surrounding teeth and soft tissues, if careful isolation of the operating area is not performed. When etching with hydrofluoric acid, the surrounding teeth and soft tissues should be protected with cream, the etchant should be removed with cotton roll, and the area should be rinsed using high-volume suction. Several alternative techniques have been proposed to replace the use of hydrofluoric acid gel in bonding to porcelain surfaces, such as the application of acidulated phosphate fluoride (APF) gels or laser etching.

Li et al. (2000) prepared porcelain with 0.6, 0.9, and 1.2-W Nd:YAG lasers for bonding and concluded that this type of laser in combination with light cure composites created acceptable bond strength to porcelain. It appears that using an $\mathrm{Nd}$ :YAG laser not only eliminates the need to rough up the porcelain, it would also eliminate the potential gingival burns associated with HF acid and the need to repolish the porcelain at deband. Furthermore, etching time is considerably shorter with the Nd:YAG laser compared to HF 
acid (10 s vs. 3-5 min). The advantage of the Nd:YAG laser in improving the shear bond strength of titanium ceramic interface was also shown by Kim and Cho (2009). A 2-W CO2 laser in superpulse mode was also found to be appropriate for orthodontic bracket bonding to deglazed porcelain surfaces. Akova et al. (2005) believe that the increased bond strength observed in the laser-treated group is related to micromechanical retention.

Poosti et al. (2011) evaluated the shear bond strength of metal orthodontic brackets to porcelain following conditioning by Er:YAG (2-W for $10 \mathrm{~s}$ and 3-W for $10 \mathrm{~s}$ ) and Nd:YAG $(0.8-\mathrm{W}$ for $10 \mathrm{~s})$ lasers in comparison to conventional methods. The results revealed that $\mathrm{Nd}$ :YAG laser was shown to be an acceptable substitute for hydrofluoric acid while Er:YAG laser with the mentioned power and duration was not a suitable option.

\subsection{Increasing the acid resistance of enamel to prevent formation of white spot lesions}

One of the most important problems during orthodontic treatment is the occurrence of enamel demineralization around orthodontic appliances. Fixed orthodontic appliances facilitate the adherence of food particles and make tooth brushing more difficult, resulting in increased amount of bacterial plaque around orthodontic attachments. The organic acids produced by oral bacteria dissolve calcium and phosphorus ions from enamel surface, creating the initial sign of demineralization, namely white spots lesions. These lesions are more commonly seen in upper anterior teeth and upper and lower premolars.(Lovrov et al., 2007) The incidence of white spot lesions is significantly higher in orthodontic patients than untreated subjects.(Tufekci et al., 2011) The clinical study of Ogaard et al (1988a) indicated that white spot lesions can be seen in as early as 4 weeks under unfitted orthodontic bands, implying the rapid progression of demineralization around orthodontic attachments. White spot formation is considered a great problem in orthodontic patients, because it detracts from the aesthetic results of treatment and may compromise tooth health by progression to caries cavity. Therefore prevention of caries formation is of great importance in orthodontic patients, especially for those with poor oral hygiene.

There have been extensive attempts to find a method to reduce the incidence of demineralization in orthodontic patients. Some studies (Ogaard et al., 1988b) indicated the efficacy of using daily fluoride mouth rinse in reducing the occurrence of white spot lesions during orthodontic treatment, but excellent cooperation in using a mouth rinse can be achieved in only $13 \%$ of patients.(Geiger et al., 1992) Another method to prevent demineralization is to use fluoride releasing composite resins or conventional or resin modified glass ionomer cements for bonding orthodontic attachments,(Dubroc et al., 1994; Marcusson et al., 1997) but some studies (Cook and Youngson, 1988; Fox et al., 1991; Klockowski et al., 1989) reported lower bond strength when using these adhesives, compared to conventional composite resins. Recently, amorphous calcium phosphate (ACP) agents have been considered as promising agents for increasing enamel resistance to decalcification and also to treat white spot lesions in orthodontic patients. Rose $(2000 \mathrm{a}, \mathrm{b})$ indicated that casein phosphopeptide-amorphous calcium phosphate (CPP-ACP) agent effectively binds with dental plaque, providing a large reservoir of readily available calcium to inhibit demineralization and also to assist remineralization. Despite improvements in materials and preventive measures, enamel demineralization continues to be a great concern for both orthodontists and patients. Therefore, finding new prophylactic measures to prevent demineralization may be a great step towards achieving healthy and aesthetic teeth at the end of treatment. 
In 1965 Sognnaes and Stern were the first to report that when the enamel was exposed to ruby laser irradiation, the resistance of enamel to acid attack was improved. To confirm the previous report of Sognnaes and Stern, Yamamoto and Sato (1980) embedded small pieces of lased enamel into several parts of human dentures. After three months, the unlased area of the enamel showed chalky white lesions, whereas no detectable visible change was observed in the lased area. Subsequently, several investigations have demonstrated that treatment with various lasers can reduce the rate of subsurface demineralization in enamel (Nelson et al. 1986, Nelson et al. 1987, Powell et al. 1994, Qiao et al. 2005). There are several theories regarding the mechanisms by which laser irradiation enhances enamel resistance. These theories range from a surface melting through partial fusion and recrystalization of enamel prisms to changes in the enamel's organic matrix (Wigdor et al. 1995). A number of studies have also shown that combining laser irradiation with fluoride treatment could have a synergistic effect on acid resistance (Goodman \& Kaufman 1977, Flaitz et al. 1995, Hicks et al. 1993, Hicks et al. 1994, Hicks et al. 1995, Hicks et al. 1997, Moslemi et al. 2009).

Using quantitative microradiography, argon laser irradiation of enamel reduced the amount of demineralization by 30-50\% (Duncan et al. 1993, Powell et al. 1994). Fox, Duncan and Otsuka (1992) found that, in addition to decreasing enamel demineralization and loss of tooth structure, $\mathrm{CO} 2$ laser treatment reduced the threshold $\mathrm{pH}$ at which dissolution occurred by about a factor of five. Lenz et al. (1982) have suggested that the enamel surface is sealed by the laser and is less permeable for the subsequent diffusion of ions into and from the enamel.

In 2001, Hossain et al. used an Er,Cr:YSGG laser to irradiate the enamel or dentin samples at $6 \mathrm{~W}(67.9 \mathrm{~J} / \mathrm{cm} 2)$ or $5 \mathrm{~W}(56.6 \mathrm{~J} / \mathrm{cm} 2)$ pulse energy, respectively, with or without water mist. The results suggested that Er,Cr:YSGG laser irradiation appears to be effective for increasing acid resistance. SEM observations showed that the lased areas were melted and seemed to be thermally degenerated. After acid demineralization, the thermally degenerated enamel or dentin surfaces were almost unchanged. In 2005 Qiao et al. irradiated the enamel and dentin samples with the Er,Cr:YSGG laser at 6 or $4 \mathrm{~W}$ for 6 seconds, respectively. They concluded that Er,Cr:YSGG laser irradiation is effective for increasing the acid resistance of dental hard tissue and does not cause thermal side effects. Kim et al. (2006) compared the effects of Er:YAG laser ablation and of phosphoric acid etching on the in-vitro acid resistance of bovine enamel and found that reduction rate and reduced depth of calcium content along the subsurface was lowest in Er:YAG laser-treated enamel than the acid etched enamel. Hence, they concluded that the Er:YAG laser-treated enamels were more resistant to acid attack than phosphoric acid-etched enamels.

According to these results it may be concluded that laser treatment of enamel of caries vulnerable areas such as around brockets would be a useful strategy in orthodontic patients. However, this would demand further investigation.

\subsection{Bracket debonding}

Ceramic brackets were introduced in the mid 1980s to supply the demands of orthodontic patients for more aesthetic and invisible appliances. However, ceramic materials have some innate defaults that preclude easy application of them in orthodontics. The low fracture toughness of ceramics may cause partial or complete bracket fracture during removal. This precludes reuse of the same bracket at a corrected position and may result in eye damage, ingestion or aspiration of bracket fragments. In addition, removal of bracket fragment on the tooth may require the use of diamond burs, a process that is time consuming and can 
damage the pulp (Vukovich et al., 1991) and enamel surface.(Chen et al., 2007) Another problem with clinical application of ceramic brackets is the high incidence of enamel damage during debonding. Enamel damage, either in the form of enamel fracture or enamel crack, detracts from esthetics of the tooth and may need costly restorative treatment and also can compromise the tooth integrity by increasing the risk of eventual tooth fracture. When the required force for bracket removal exceeds the cohesive strength of the enamel, fracture of the enamel surface is inevitable. The debonding stress of ceramic brackets can exceed $20 \mathrm{MPa}$, (Theodorakopoulou et al., 2004; Gwinnett, 1988; Odegaard and Segner, 1988) and these forces may be sufficient to fracture the enamel and create severe discomfort in patients who their teeth have been mobilize by orthodontic treatment.(Tocchio et al., 1993)

For debonding of ceramic brackets, special pliers have been used conventionally to apply a sufficiently high force to fracture the bond. However, ceramic brackets are brittle and cannot be removed easily by pliers. Enamel damage and bracket fracture have been reported frequently with conventional debonding of ceramic brackets (Artun, 1997; Bishara et al., 2008; Joseph and Rossouw, 1990) due to the high bond strength combined with the low fracture toughness of ceramics. Some alternative methods have been proposed for weakening the bond immediately before debonding, including ultrasonic and electro thermal devices.(Bishara and Trulove, 1990a; Brouns et al., 1993; Bishara and Trulove, 1990b) With electrothermal method, adhesive resin is softened above a critical temperature (approximately 150 to $200^{\circ} \mathrm{C}$ ) to allow removing the brackets at a significantly reduced force level.(Strobl et al., 1992) The main drawback of instruments that use electric heat element as a heat source is that there is no quantitative control on the amount of delivered heat energy to ceramic bracket, which in turn may excessively heat the tooth during bracket removal. Some studies reported pulp damage after use of electrothermal devices for debonding of ceramic brackets.(Dovgan et al., 1995; Jost-Brinkmann et al., 1992) and consequently these methods failed to achieve popularity among orthodontists.

Since the early 1990s, lasers have been used experimentally for debonding of ceramic brackets. The use of lasers eliminates problems such as enamel tear outs, bracket failures, and pain that are encountered during conventional ceramic bracket removal techniques. Additionally, lasers have the advantage of decreasing debonding force and operation time (Strobl et al. 1992, Tocchio et al. 1993, Mimura et al. 1995, Rickabaugh et al. 1996, Ma et al. 1997, Obata et al. 1999, Abdul-Kader et al. 1999, Hayakawa 2005, Xianglong et al. 2008).

In most previous studies, carbon dioxide lasers whose wavelength is more easily absorbed by the ceramic brackets had been preferred for debonding. Strobl et al. (1992) investigated the removal of polycrystalline and monocrystalline alumina brackets using carbon dioxide and YAG lasers. Their results showed that laser-aided debonding significantly reduced debonding force by thermal softening of the resin. It was also concluded that with the $\mathrm{Nd}$ :YAG laser, approximately $69-75 \%$ of the incident light reached the enamel surface, which has the potential to cause pain or damage to the tooth structure.

Mimura et al. (1995) used a carbon dioxide laser to investigate the differences in the laseraided debonding mechanism between 2 adhesives. Unlike previous studies, they applied the force and the lasing simultaneously. They concluded that the laser-focused adhesives tended to be removed with the brackets in the Bis-GMA groups, whereas the adhesives tended to remain on the tooth surface in the MMA groups.

Rickabaugh et al. (1996) and Ma et al. (1997) used carbon dioxide lasers and modified debonding pliers to accurately position the laser beam on the ceramic bracket. In accordance 
with previous studies, their results showed significant differences in tensile debonding forces between the control and study groups. They also stated that the bracket could be removed from the tooth with pliers as soon as the adhesive-softening temperature had been reached, and the debonding pliers holding the bracket reduced the possibility of dropping it on the patient. Additionally, quick removal of the bracket prevented the heat energy stored in the bracket from transmitting to the tooth.

Iijima et al. (2010) suggested that the mechanical properties of tooth enamel such as hardness and elastic modulus were not affected by CO2 laser irradiation. Obata et al. (1999) debonded ceramic brackets with the aid of super and normal pulse CO2 lasers. They showed that a Super pulse CO2 laser is better than a continuous one. As they minimized the power levels of the super pulse CO2 laser, they obtained a smaller intrapulpal temperature increase compared to the normal pulse laser. The investigators concluded that using a super pulse CO2 laser for debonding did not cause a risk for the pulp. Recently, Tehranchi et al. (2010) evaluated the effect of super pulse CO2 laser (power density of $50 \mathrm{~W}$, exposure time of $5 \mathrm{~s}$, and duration pulse of $500 \mu \mathrm{s}$ ) on shear bond strength and adhesive remnant index during debonding of ceramic brackets. They showed less debonding force and more adhesive remnant index on the tooth surface in the laser group.

Tocchio et al (1993) used Nd:YAG laser light at wavelengths of 248, 308, and $1060 \mathrm{~nm}$ at power densities between 3 and $33 \mathrm{~W}$ per square centimeter to debond 2 types of ceramic brackets by externally applied stress of either 0 or $0.8 \mathrm{MPa}$. No enamel or bracket damage was reported as a result of laser debonding. According to the investigators, laser energy can degrade the adhesive resin by thermal softening, thermal ablation, or photoablation. This mechanism causes rapid thermal expansion or burnout and vaporization of the resin, causing a small explosion. The pressure generated by the explosion functions as the debonding force. The rise in intrapulpal temperature as a result of lasing was extremely low, and the maximum temperature increase was $5.1^{\circ} \mathrm{C}$.

A high peak Nd:YAG laser at $2.0 \mathrm{~J}$ (1.2-ms pulse duration, 5 pulse per second) was used by Hayakawa (2005) to develop an effective method for debonding ceramic brackets. Even though the Nd:YAG laser has a higher degree of enamel transmissibility than the CO2 laser, it has a lower ceramic absorption level that will directly influence the resin by enhancing the effects of thermal ablation and photoablation. In this study, very short lasing time caused an instantaneous resin reaction that produced a localized, instantaneous temperature increase. The investigator stated that the intrapulpal temperature had not increased much (maximum rise was $5.1^{\circ} \mathrm{C}$ ), probably because of this instantaneous reaction of the adhesive resin to the laser. Although the laser energy delivered was too small compared to Strobl et al.'s (1992) application, it was effective because of the millisecond pulses with high peak powers.

Oztoprak et al. (2010) preferred the Er:YAG laser since it has a lesser thermal effect than the Nd:YAG or CO2 laser (Wigdor et al. 1993). They stated that Er:YAG laser is effective for reducing the shear bond strengths of orthodontic polycrystalline ceramic brackets from high values to levels for safe removal from the teeth. These investigators developed a new method to debond ceramic brackets by scanning thoroughly the surface of the brackets for 9 s. This was confirmed by Nalbantgil et al. (2010) which stated that $6 \mathrm{~s}$ lasing with the scanning method using the Er:YAG laser may be an effective and safe way to remove ceramic brackets without causing intrapulpal and enamel damage.

Ahrari et al. (2011) used ultra pulse CO2 laser $(188 \mathrm{~W}, 400 \mathrm{~Hz})$ for deboning of chemicallyretained and mechanically-retained ceramic brackets and reported that laser-assisted debonding reduced the risk of enamel damage and bracket fracture, and produced the more desirable ARI scores, without causing thermal damage to the pulp. 
Yet laser wavelength and mode of operation (continuous pulsed or modulated) should be chosen properly in order to prevent any thermal hazard given to the enamel or pulp.

\subsection{Laser welding}

Today, most orthodontic appliances are fabricated by joining of different individual components together. However, in-office fusion of wires or other attachments to orthodontic appliances is still a common procedure for construction or repair of appliances during orthodontic treatment to achieve optimal treatment results. In orthodontics, as in other parts of dentistry, fusion can be achieved through soldering, brazing or welding. The only difference between soldering and brazing is the liquidus temperature of intermediate alloy.

\subsubsection{Soldering}

In soldering, the metal parts are joined by heating them at temperatures below the solidus temperature of substrate metal. A filler metal with liquidus temperature not more than $450^{\circ} \mathrm{C}$ is applied. The filler metal melts and flows through the interface without affecting the dimension of the joined structure.(Chandra et al, 2000)

Two methods are used for producing the necessary heat to melt the filler: gas blow torch and electrical resistance soldering. The use of gas blow torch is less expensive, but the heat is much more localized in electrical resistance soldering. It should be noted that the interface between a silver solder and stainless steel is more mechanical than alloying, therefore adequate amount of solder should be used to reinforce the junction. (van Noort, 2002)

\subsubsection{Brazing}

In brazing, the liquids temperature of filler metal is above $450^{\circ} \mathrm{C}$ and below the solidus temperature of the base metal. Similar to soldering, the filler metal melts and flows, joining metal parts together without affecting the dimensions of the joined structure. Brazing is a common procedure to join the components of orthodontic appliances such as base and wing components of brackets. However, brazing alloys contain traces of cytotoxic cadmium, and also form a galvanic couple that can lead to ionic release of mainly copper and zinc elements. (Eliades, 2007)

\subsubsection{Welding}

Welding defines the joining of two metal pieces by applying heat, pressure, or both, without the use of an intermediate alloy. In welding, fusion takes place by metallic bonding through a localized union across the interface. Welding is commonly used for joining flat structures such as band or brackets. The only orthodontic wire material that is truly capable of being welded is $\beta$-Titanium. Stainless steel is also can be welded to stainless steel, but the joint is not very strong and should be reinforced with solder. Nickel titanium wires cannot be welded or soldered.(Ferracane, 2001)

There are three ways of welding in dentistry.

Pressure welding: Pressure welding is achieved by applying a sufficiently large force to the metal parts to be joined. Pure gold foils can be pressure welded by hand or mechanical condensers.

Spot (resistance) welding: Welding at a spot is called spot welding. This process is used to join flat structures, such as orthodontic bands and brackets and also to join some types of orthodontic wires. In spot welding, the parts to be joined should be pressed firmly together 
between two electrodes usually made of copper. Then a high electric current is passed through the system, and since the parts to be joined are less conductive of electricity than the copper electrodes, they will heat up and create a fused localized melted joint. Usually a current of 250 to 750 amperes is used, for a time of between 1/25th and 1/50th second.(Combe, 1981) Spot welding is successful in formation of overlapping joints of stainless steel or other chromium-containing alloys, but should not be used for gold alloys, since they are good conductors of electricity. Electrical resistance welding is suitable for $\beta$-Ti wire, the only orthodontic wire that has true weldability.

The strength of the welded joint is enhanced by an increase in the weld area. However, the welded area becomes brittle and susceptible to corrosion, because of precipitation of chromium carbide at temperatures above 500C, a process that is known as weld decay. Therefore, small welds are generally considered better, because fusion is achieved with minimal changes in the original grain structure.

Laser welding: Another method employed for joining metal frameworks is laser welding. To weld dental alloys, Nd:YAG laser is mainly used (Yamagishi et al., 1993; Liu et al., 2002; Iwasaki et al., 2004; Watanabe and Topham, 2004, 2006; Srimaneepong et al., 2005; Watanabe et al., 2006).

In laser welding, laser light is focused on small regions, applying high energy to these areas in a very short amount of time. Heating is mainly focused at the point of application; therefore the surrounding areas do not damage. (O'Brien, 1997) In some studies, laser welded joints showed greater mechanical resistance than that achieved by traditional welding.(Fornaini et al., 2010)

Titanium alloys are commonly used in dentistry for crowns, bridges, partial denture frameworks, and also for orthodontic wires. These cannot be easily soldered by traditional torch-soldering or oven-soldering procedures. This is related to the fact that at temperatures used for soldering procedures, the thickness of the titanium oxide layer increases and it may even debond from the metal surface at higher temperatures. For effective joining of components made of pure titanium, laser welding is a preferred method, because it is associated with a lower thermal influence on the parts being joined, preserves the excellent biocompatibility potential of pure titanium and prevents the risk of galvanic corrosion. (Anusavice, 2003)

Laser welding is recently used in bracket manufacturing as an alternative to brazing. This technique eliminates the need to brazing alloy, reduces the risk of corrosion, and provides acceptable mechanical performance in association with a low risk of joint failure. (Eliades, 2007)

Solmi et al. (2004) analyzed the adhesion and proliferation of human gingival fibroblasts placed in direct contact with conventionally soldered and laser-welded orthodontic joints for up to 16 days. Significant differences in counts of survival fibroblasts were observed at all experimental times. The fibroblasts on both the laser-welded and control substrates showed similar patterns. By contrast, on the substrate of the soldered samples, the fibroblasts showed no sign of adaptation at any time during the study. These results highlight the superior biocompatibility of laser welding over brazing.

Testing the cell reactions of osteoblasts, fibroblasts, and keratinocytes, Sestini et al. (2006) found a good tolerance of electrical resistance and laser welding, while traditional silver solder was toxic for osteoblast differentiation, fibroblast viability, and keratinocyte growth. 
The influence of brazing or welding on tensile strength has not been uniformly determined. In different studies, the factors affecting the mechanical strength of welded joints have been described: wavelength, peak pulse power, pulse energy, output energy, pulse duration, pulse frequency, and spot diameter of the laser welding machine and the type of metal used (McCartney and Doud, 1993; Yamagishi et al., 1993; Taylor et al., 1998; Watanabe et al., 2001, 2003, 2004, 2006; Yan and Yang, 2006). Chai and Chou (1998) showed an equal or superior mechanical strength of the welded sites compared with the unsectioned parent metal of different $\mathrm{Ti}$ alloys depending on welding conditions. In contrast, the fracture load of unwelded $\mathrm{Ti}$, gold, or Co-Cr alloys in different configurations of laser welding were not achieved (Watanabe et al., 2001, 2003, 2004, 2006). Especially for gold and Co-Cr alloys, only 50 per cent or less of the original measurements were found. In the study by Bertrand et al. (2004), a small change in the chemical composition of the Ni-based alloys caused an important difference in weldability.

Rocha et al. (2006) compared laser and TIG welding of non-precious alloys. TIG welding increased the flexural strength of $\mathrm{Ti}, \mathrm{Co}-\mathrm{Cr}$, and $\mathrm{Ni}-\mathrm{Cr}$ as the used welded cylinders presented higher flexural strength than the non-weld cylinders. The highest means were observed for $\mathrm{Co}-\mathrm{Cr}$ weld by TIG and non-welded $\mathrm{Co}-\mathrm{Cr}$. By contrast, laser welding achieved only 17.5 per cent of the flexural strength of $\mathrm{Co}-\mathrm{Cr}$ alloy. When joining $\mathrm{Co}-\mathrm{Cr}$ alloy specimens, Zupancic et al. (2006) showed significant differences between brazing and laser welding. Those authors estimated a low penetration depth, peripheral overheating, porosities, and carbon content of the alloy as possible reasons for the relative weakness of laser welding.

The evaluation of three orthodontic arch wire alloy materials, stainless steel, beta titanium, and Timolium, for their laser-weld characteristics showed significantly different tensile strength values between these materials (Krishnan and Kumar, 2004). Although a comparison with original wires was not carried out in that study, it could be assumed that laser-welded specimens showed a significantly lower tensile strength than pure metals.

More recently Bock et al. (2008) showed that small changes in laser welding parameters significantly influenced the mechanical properties of orthodontic wires. Although laser welding is a solder-free alternative for orthodontic purposes, further investigations are needed to determine the optimal parameters.

\subsection{Laser minor surgery}

Laser surgery offers numerous advantages compared with traditional scalpel surgery. Softtissue excision is more precise with a laser than a scalpel (Rossman and Cobb 1995). A laser coagulates blood vessels, seals lymphatic, and sterilizes the wound during ablation, maintaining a clear and clean surgical field. The use of soft-tissue lasers result in a shorter operative time and faster postoperative recuperation (Sarver and Yanosky 2005). Laser surgery is routinely performed by using only topical anesthetic, which is particularly beneficial in an open orthodontic clinic (Sarver 2006). There is markedly less bleeding (particularly for frenal surgery), minimal swelling, and no need for irritating sutures or unsightly periodontal dressing (Haytac and Ozcelik 2006). Post surgically, patients report less discomfort and fewer functional complications (speaking and chewing), and require fewer analgesics than do patients treated with conventional scalpel surgery (Haytac and Ozcelik 2006).

The primary disadvantage of laser surgery is its high expense. Some clinicians have reported greater tactile sense with a scalpel (which might be particularly true for noncontact 
soft-tissue lasers such as the erbium laser), tissue desiccation, and poor wound healing (Baker et al. 2002).

Lasers cut by thermal ablation-decomposition of tissue through an instantaneous process of absorption, melting, and vaporization. Essentially, the cells of the target tissue absorb the concentrated light energy, rapidly rise in temperature, and produce a micro-explosion known as spallation (Moritz 2006).

Surgical lasers typically have (1) a central zone of carbonization surrounded by, (2) a zone of vaporization, coagulation, and protein denaturation, and (3) a stimulating zone. This may be one reason for the improved healing with laser surgery compared with traditional scalpel surgery. During laser curettage, sufficient hemostasis and significant reduction of the initial levels of periodontal pathogens are achieved (Lioubavina-Hack 2002). Various applications of laser surgery in orthodontics are:

\subsubsection{Gingival enlargements, gingival hyperplasia and reshaping gingival shape and contours}

Sometimes removal of excessive gingival tissues is necessary to provide optimal display of teeth. For example, inadequate tooth display in smile in an adolescent patient may be related to altered passive eruption or gingival encroachment, making the teeth appears short. In this cases, gingivectomy may provide sufficient tooth display and appropriate tooth proportions.

Gingival hyperplasia is commonly observed during orthodontic treatment, especially in patients with poor oral hygiene. Generally, it is preferred to postpone treatment of gingival hyperplasia until the end of orthodontic treatment, unless the gingival tissue or enlargement interferes with tooth movement. If this occurs, the excess gingiva must be removed surgically during the treatment. Orthodontists should also consider gingival shape and contour of the teeth and make necessary corrections to provide optimal treatment results at the end of orthodontic treatment. Recontouring gingival shape and contour can be readily accomplished in the orthodontist's office with a diode laser. Laser gingivectomy has advantages such as minimal bleeding and postoperative pain and no swelling (LioubavinaHack 2002). Correction of gingival hyperplasia can also be performed easily with the aid of laser light.

\subsubsection{Fibrotomy}

Fibrotomy (Pericision) is frequently indicated to provide long term stability of teeth with severe rotations before treatment. This procedure is usually performed for upper and lower anterior teeth (e.g. maxillary lateral incisors in class II Div 2 patients) where maintaining treatment results is of great importance. Fibrotomy or severing of transpalatal fibers should be performed at the end of orthodontic treatment and before appliance removal.(Vanarsdall RL and Secchi AG, 2005) The teeth should be held in good alignment after fibrotomy when gingival healing occurs.

The poor patient acceptability in conventional fiberotomy, as an invasive procedure, suggests that an alternative technique needs to be considered. Kim et al. (2010) investigated the effectiveness and periodontal side effects of laser circumferential supracrestal fibrotomy (CSF) of orthodontically rotated teeth in beagles. A gallium-aluminum-arsenide (Ga-Al-As) diode laser with an 808-nm wavelength and 0.4-mm fiber diameter was used. The laser tip was inserted into the gingival sulcus to the level of the alveolar bone crest, and the incision 
was extended around the tooth circumference with the system configured to the soft tissue cutting mode (continuous wave; $1.2 \mathrm{~W}$ ). The amount of relapse, sulcus depth, and gingival recession were measured at weeks 4 and 8 . They concluded that laser CSF is an effective procedure to decrease relapse after tooth rotation, causing no apparent damage to the supporting periodontal structures. It was claimed that the bactericidal effect transferred by the laser within the periodontal pocket can reduce the risk of infection.

\subsubsection{Frenectomy}

Frenectomy is usually indicated to prevent relapse after correction of midline diastema. Before eruption of maxillary canines, small physiologic spaces usually exist between maxillary incisors, a developmental stage named "ugly duckling stage". These spaces tend to close spontaneously after eruption of maxillary canines. Therefore frenectomy is not indicated during mixed dentition treatment, unless the presence of a large diastema between central incisors causes a great aesthetic problem, or prevents the eruption of other anterior teeth. When frenectomy is indicated, it is recommended to close the space between central incisors with orthodontic treatment prior to frenectomy. Otherwise, the formation of scar tissue prevents orthodontic space closure. Of course in some occasions, the presence of a very thick frenum may prevent space closure. If this occurs, frenectomy should be performed after partial space closure, and orthodontic treatment should be resumed immediately after frenectomy to complete space closure. In the conventional surgical method a simple incision is used to allow access to the interdental area, the fibrous connection to the bone is removed, and the frenum is then sutured at a higher level.

Olivi et al. (2010) clinically evaluated the efficacy of Er,Cr:YSGG laser at a power setting of $1.5 \mathrm{~W}$ or less in 156 frenectomies. The reported very high patient acceptance and no postoperative adverse events. Recently diode laser frenectomy without infiltrated anesthesia was suggested by Kafas et al. (2009). They concluded that this procedure have optimum healing post-surgically. However, in severe cases of soft tissue excision the need of anesthesia may be essential (Kato and Wijeyeweera 2007).

Haytac and Ozcelik (2006) reported that CO2 laser treatment used for frenectomy operations provides better patient perception in terms of postoperative pain and function than that obtained by the scalpel technique. They suggested that CO2 laser offers a safe, effective, acceptable, and impressive alternative for frenectomy operations. The results were the same for Nd:YAG laser frenectomy. Kara (2009) compared the effects of Nd:YAG laser and conventional technique on the degree of preoperative anxiety levels, postoperative pain, discomfort, and functional complications (eating and speech) of frenectomy. The results suggested that Nd:YAG laser treatment of soft tissue disorders provides better patient perceptions of success than those seen with conventional surgery.

\section{Low intensity laser therapy in orthodontics}

\subsection{Description of therapeutic lasers}

Low level laser therapy (LLLT) is also known as "soft laser therapy" and bio-stimulation. The use of LLLT in health care has been documented in the literature for more than three decades. Numerous research studies have demonstrated that LLLT is effective for some specific applications in dentistry. The LLLT literatures are large, with more than 1,000 papers published on this topic. A problem in dissecting this literature is the variation in methodology and dosimetry between different studies. Not only have a range of different 
wave lengths been examined, but exposure times and the frequency of treatments also vary (Walsh et al,2006).

While broad band light can exert effects on cells, interest has been concentrated on using lasers as a light source because of their greater therapeutic effect (Karu. 1989, Laakso et al. 1993). While much of the initial work with LLLT used the helium - neon gas laser work with LLLT used the helium- neon gas laser $(\lambda=632.8 \mathrm{~nm})$, nowadays most LLLT clinical procedures are undertaken using semiconductor diode lasers, for example, gallium arsenide based diode lasers operating at $\lambda=830 \mathrm{~nm}$ or $\lambda=635 \mathrm{~nm}$ wavelengths. Since wavelength is the most important factor in any type of phototherapy, the clinician must consider which wavelengths are capable of producing the desired effects within living tissues. The typical power output for a low level laser device used for this therapy is of the order of $10-50 \mathrm{~mW}$, and total irradiances at any point are of the order of several Joules. Thermal effects of LLLT on dental tissues are not significant, and do not contribute to the therapeutic effects seen. The wavelengths use for LLLT has poor absorption in water, and thus penetrate soft and hard tissues from $3 \mathrm{~mm}$ to up to $15 \mathrm{~mm}$ (Sandford \&Walsh.1994;Ohshiro \& Calderhead.1998; Walsh.2003; Walsh et al.2006).

\subsection{History}

In 1967, a few years after the first working laser was invented, Endre Mester in Semmelweis University, Budapest, Hungary wanted to test if laser radiation might cause cancer in mice (Mester, 1968). They did not get cancer, and to his surprise the hair on the treated group grew back more quickly than the untreated group. This was the first demonstration of "laser biostimulation". In fact, light therapy is one of the oldest therapeutic methods used by humans historically as solar therapy by Egyptians, later as UV therapy for which Nils Finsen won the Nobel Prize in 1904. (Roelandts,2002).

The use of lasers and LEDs as light sources was the next step in the technological development of light therapy, which is now applied to many thousands of people worldwide each day. The reason why the technique is termed LOW-level is that the optimum levels of energy density delivered are low when compared to other forms of laser therapy as practiced for ablation, cutting, and thermally coagulating tissue. In general, the power densities used for LLLT are lower than those needed to produce heating of tissue, i.e., less than $100 \mathrm{~mW} / \mathrm{cm} 2$, depending on wavelength and tissue type (Huang YY et al., 2009).

\subsection{Introduction}

Although laser phototherapy ("low level laser therapy") has been practiced for more than 30 years there is still controversy regarding its scientific standard. Questions still remain even though more than 400 studies with a dental focus have been reported. The biomodulative effects exerted on cells are well documented (Karu 2003, 2006, 2007), to a certain degree in animal studies. The safety of the treatment is also well documented. In spite of clinical observations for a great variety of conditions, some controversy remains.

Due to the fact that so many parameters are included, it is more difficult to reach a consensus in this area of dental laser applications than in the domain of high-intensity laser applications. Many different wavelengths, power densities, energy densities and application modes have been used and there is no current consensus about optical standards. In addition, the reporting of the actual laser parameters and dosimetry in studies is often substandard and control studies are therefore difficult to perform. Consequently the 
evaluation of the various applications becomes problematic. The optical properties and performance of the various commercially available lasers vary widely, adding to the problems in the evaluation process (Bradley \& Tuner, 2007).

Surgical lasers are rather precise in their indications: the results are verified more easily with the naked eye as well as through subsequent lab analyses. Therapeutic lasers work on the cellular level, influencing the fundamental functions of the cells. Any pathological condition can thus theoretically be improved if the suitable wavelength and energy of light is applied. This is at the same time the beauty and the problem of laser biomodulation: how can one therapy be applied in so many situations? There is supposedly no universal method in the history of medicine and a skeptical attitude from dentists is basically a sound reaction. The results of non-dental research often have to be extrapolated into dental area when conclusions are to be attempted. It should to a high degree of probability be possible to extrapolate the effects on nerves, wound healing, pain relief, edema, etc., and in non- dental areas of the animal or human body for dental conditions. A problematic part of the existing literature is the frequent lack of understanding of laser physics and laser therapeutic approaches, whether from manufacturers, users, researchers or indeed from peer reviewers(Bradley \& Tuner, 2007).

Several meta-analyses have failed to evaluate crucial dosimetric parameters such as applied energies and energy densities, and later re-evaluations using the same material have been able to turn a negative interpretation into positive on (Bjordal et al. 1998, 2001, 2003). But once published, meta analyses are irrepressible. Even Cochrane analyses of laser interventions (Bjordal 2005) have failed to observe basic analysis of doses, wavelengths and application modes. Future studies had better address the most crucial parameter of the study, namely the laser itself. Consensus is needed on how to describe these parameters.

The phenomenon of cell biomodulation is well described (Karu 2003), but the optimal clinical parameters are still little known and will have to be more accurately defined in future studies. Many positive studies were conducted within a supposed "therapeutic window" but were not necessarily close to the optimal applications. The most important fields of future research will be discussed here. Laser phototherapy is non- invasive, nonpharmaceutical, has very few side effects, is painless and enjoys a high acceptance from patients. More attention to the method's potential is therefore logical .A not so well-known fact that should be recognized, is that surgical lasers can have a biomodulatory effect, too. Furthermore, all these "surgical" lasers can be used for biomodulation purposes if the dosage is adjusted accordingly. To further emphasize this fact would increase the value of a surgical laser (Bradley \& Tuner, 2007).

\subsection{Mechanism of action}

The mechanisms of low level laser therapy are complex, but essentially rely upon the absorption of particular visible red and near-infrared wavelengths in photoreceptors within sub-cellular components, particularly the electron transport (respiratory) chain within the membranes of mitochondria(Karu.1989a,1989b; Walsh et al,2006).

The absorption of light by the respiratory chain components causes a short- term activation of the respiratory chain, and oxidation of the NADH pool. This stimulation of oxidative phosphorylation leads to changes in the redox status of both the mitochondria and the cytoplasm of the cell. The electron transport chain is able to provide increased levels of promotive force to the cell, through increased supply of ATP, as well as an increase in the 
electrical potential of the mitochondria membrane, alkalization of the cytoplasm, and activation of nucleic acid synthesis. Because ATP is the "energy currency" for a cell, LLLT has a potent that results in simulation of the normal functions of the cell(Yu et al.1997;Walsh et al, 2006).

Karu.(1987,1988,1989)who has studied the bio-stimulative effects of light on cell cultures in great detail, has demonstrated that cell cultures that are initially irradiated with laser light show a range of biological effects. Of importance, is these cultures are then irradiated with non- monochromatic and incoherent light, the previous laser- produced biological effects are almost nullified. This suggests that there are more complex mechanisms at work than the simple excitation of polarization- sensitive chromophores in the cell. Considerable insight into the effect of wave length on LLLT has been gained from the work of Karu who over a period of years has conducted extensive research using cell cultures of various types. Her work has provided and action spectrum for bio-stimulation of the rate of DNA synthesis in HeLa cells, and for proliferation of bacteria and yeast colonies. These spectra show peaks in the blue $(\lambda=404 \mathrm{~nm}$ and $\lambda=454 \mathrm{~nm})$, red $(\lambda=620 \mathrm{~nm})$, and near-infrared $(\lambda=760 \mathrm{~nm})$ and $\lambda=830 \mathrm{~nm})$. (Karu,1987,1988,1989). The tissue response to photonic energy as well as to other energetic stimuli follows the Arndt Schultz pattern where low energies stimulated and high energies tend to inhibit.(Fig.5). It follows from this that low energies will be appropriate for the stimulation of healing while high energies may be more suitable for pain control with the aim of suppressing aberrant sensitization of nerve fibers(Bradley \& Tuner, 2007).The Arndt-Schulz law thus provides a useful theoretical basis to explain the varying photobiostimulatory and photobioinhibitory effects observed in the laboratory; however it also goes some way to accounting for the apparently conflicting results that are sometimes achieved with low-intensity laser therapy. (Fig.5)

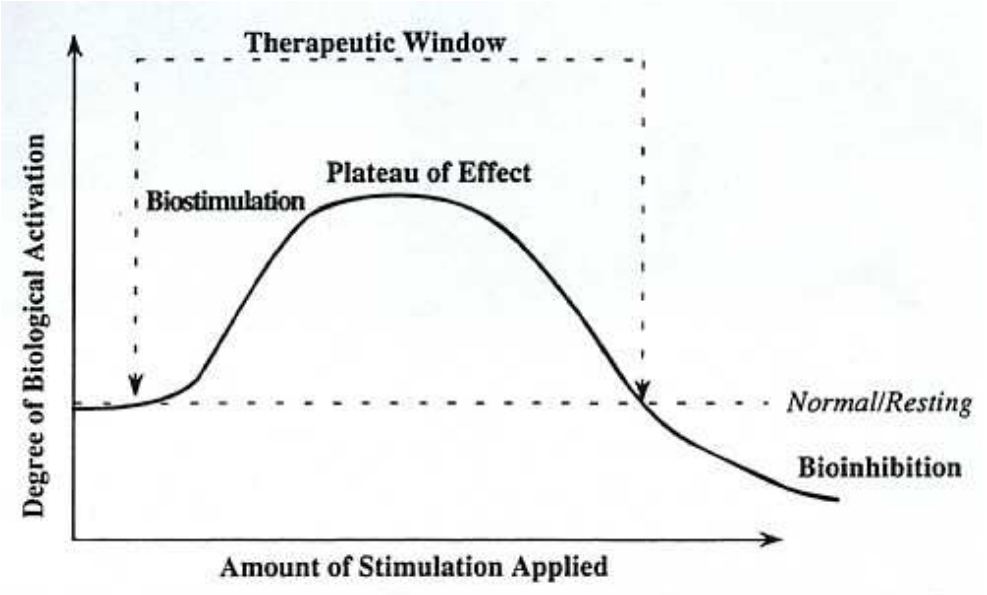

Fig. 5. Arndt-Schultz Law

This is only a generalization in that promotion of healing in an inflammatory situation may have a pain relieving action in its own right. From an extensive background of laboratory date, Dyson. (2005) has divided cellular responses in the context of healing into primary and secondary responses. 


\section{Primary responses:}

1. The photons are absorbed by cytochromes.2. Singlet oxygen free radicals are generated, effecting ATP synthesis and thus increasing the energy available to the cells.3. Nitric oxide is produced.4. Reversible increase in cell membrane permeability to calcium and other ions occurs, triggering changes in cell activity, i.e. secondary responses.

\section{Secondary responses:}

1. DNA and RNA synthesis.2. Cell proliferation.3. Growth factor release.4. Collagen synthesis by fibroblasts.5. Changes in nerve conduction, neurotransmitter release etc.

\section{Potential mechanisms of pain relief:}

The potential mechanisms involved in pain relief (Bradley, 2005) have been postulated as:

a. Direct action on nerve. There is evidence from the animal experimental field using excised rat sciatic nerve that $830 \mathrm{~nm}$ irradiation with an incident power of $60 \mathrm{mw}$ for 60 seconds (4 Jules per point) and 120 seconds (8 Joules per point) can inhibit the activity of sodium potassium ATP -ase responsible for never depolarization in generation of the action potential (Kudoh et al, 1989). This effect is likely to he maximal for the small diameter $\mathrm{C}$ fibers responsible for most chronic pain, due to their lack of a protective myelin sheath.

b. Energization of inactivated enzymes: Enzymes may be inactivated by such factors as hypoxia and acidosis in areas of muscle spasm with ischemia (e.g. trigger points) or in foci of chronic inflammation. There is evidence that laser energy can reactivate these enzymes (Bolognani \& Volpi, 1992). Free radicals for example may be a source of pain in dysfunctional muscle where the enzyme super oxide dismutase (SOD) can break down these entities if reactivated.

c. Production of Energy Molecules (ATP) in Dysfunctional Muscle. The interaction of myosin and actin in muscle requires adenosine triphosphate (ATP) and its lack may contribute to painful dysfunction. A characteristic of the response of cells to laser light is the formation of ATP (Krau, 2000).

d. Reduction of prostaglandin levels. There is evidence from the clinical and cell culture work that laser exposure can reduce levels of the algogenic substance PGE2 (Mizutani et al., 2002).

\subsection{Contraindication}

Absolute contraindications to LPT are not known, but there are several relative contradictions and caveats. Areas of malignancies or suspected malignancies should be avoided at present due to insufficient knowledge. For the same reason irradiation of patients with coagulation disorders and photosensitivity should be avoided. Irradiation over the thyroid has been reported as a contraindication, but current knowledge does not substantiate such risk when irradiation is performed in or close to this area on healthy individuals. However, care is recommended in cases of hyperthyroidism. Pregnancy is reported as a caveat, but this would only apply in case of large doses over the abdomen. As for epilepsy, there are anecdotal reports on seizure attacks triggered by pulsed light, but it would probably have to be in the visible range and observed by the patient. Irradiations over testicles and diabetic wounds have been reported as contraindications for LPT, given the correct diagnosis. Some articles mention patients wearing pacemakers as a contraindication, but this is likely a misunderstanding (Bradley \& Tuner, 2007). 


\subsection{Conclusions}

Low level laser therapy has been found to accelerated wound healing and reduce pain, possibly by stimulating oxidative phosphorylation in mitochondria and modulating inflammatory responses. By influencing the biological function of a variety of cell types, it is able to exert a rage of several beneficial effects upon inflammation and healing (Walsh et al,, 2006). LLLT exerts marked effects upon cell in all phases on wound healing, but particularly so during the proliferative phase. There is good evidence that the enhanced cell metabolic functions seen after LLLT are the result of activation of photo-receptors within the electron transport chain of mitochondria. The effects specific for wavelength, and cannot be gained efficiently with normal, non- coherent, non- polarized light sources, such as LEDs(Walsh et al.,2006).

Future trials of new LLLT applications in dentistry should make use of standardized, validated outcomes, and should explore how the effectiveness of the LLLT protocol used may be influenced by wavelength, treatment duration, dosage, and the site of application.

\subsection{Photobiomodolation effects of lasers in orthodontics \\ 4.7.1 Pain reduction}

Pain or discomfort is a common experience during fixed orthodontic treatment. Pain is usually appears several hours after orthodontic force application and slowly increases until 24 hours, then it returns to the basic level at approximately 5 th days. This pain cycle may be repeated after each appointment, although for nearly all patients, it is the most severe after initial arch wire placement. For patients, pain may be the most important side effect of orthodontic treatment and one of the main reasons for their lack of compliance or missing appointments.(Sergl et al., 1998; Turhani et al., 2006; Young et al., 2006; Bird et al., 2007; Polat et al., 2005) Furthermore, nearly all orthodontic patients report pain during chewing and biting and this can oblige them to change diet habits. Finally, it has been demonstrated that pain and discomfort during orthodontic treatment negatively affects the satisfaction of patient from aesthetic results of orthodontic treatment.(Al-Omiri and Abu Alhaija, 2006) If orthodontists are able to prevent or control pain, patients may have a better quality of life and show more tendencies to cooperate with treatment recommendations.

The mechanism through which orthodontic forces produce pain has not well recognized, but there is some evidence indicating that pain is related to the change in blood circulation of periodontal ligament, causing ischemic areas in the PDL. For this reason, a heavier force may cause a greater degree of pain due to the formation of larger ischemic areas in the periodontal ligament. Pain is also dependant to the formation of metabolic products such as prostaglandins and substance $\mathrm{P}$ which stimulate pain receptors.

To relieve pain, most orthodontists recommend their patients to use nonsteroidal antiinflammatory drugs (NSAIDs), to inhibit the formation of pain producing agents such as prostaglandins and thus reduce the pain. However, these drugs may have side effects and therefore are contraindicated in some patients. Furthermore, most drugs used for pain control can have negative effects on tooth movement if used chronically, due to their inhibitory effects on prostaglandins.

Considering the side effects of analgesics, researchers have looked for other new, but safer approaches, such as LLLT to reduce pain from orthodontic procedures (Xiaoting 2010). Although only a few studies have dealt with the response of orthodontic patients to LLLT, all concluded that LLLT reduces pain during orthodontic treatment (Lim et al. 1995, Katoh et al. 1997, Harazaki et al. 1997, Harazaki and Isshiki 1998, Turhani et al. 2006, Youssef et al 
2008). Lim et al. (1995) observed in orthodontic patients that pain for teeth irradiated with a gallium-arsenic-aluminum diode laser was lower compared with pain when a placebo was used. Harazaki and Isshiki (1998), on irradiating both vestibular and lingual sides of teeth with an orthodontic appliance, using a helium-neon laser with a 632.8-nm wavelength, operated at $6 \mathrm{~mW}$ for 30 seconds, reported that the laser therapy not only reduced patient discomfort but also delayed the onset of pain. Data have shown the efficacy of LLLT for pain control after placement of the first archwire (Turhani et al. 2006, Tortamano et al. 2009). In a study by Tortamano et al. (2009) the patients in the experimental group received galliumarsenic-aluminum diode laser irradiation with a wavelength of $830 \mathrm{~nm}$. The laser beam emitted a constant wave with a mean output of $30 \mathrm{~mW}$. Each tooth received a dose of $2.5 \mathrm{~J}$ per square centimenter on each side (buccal and lingual). The patients in the LLLT group had reduced pain duration and a lower intensity of pain. Although these authors couldn't find any effect on the start of pain perception, previous studies showed delayed pain onset in patients who had LLLT (Harazaki 1997, Turhani 2006).

Overall, based on the efficacy of LLLT to control pain in orthodontic treatment, LLLT could be recommended for pain control during fixed orthodontic appliance therapy. The reason for reducing its clinical use seems to be the total time (32-37.5 minutes) for application to both dental arches (Lim et al. 1995, Katoh et al. 1997, Harazaki et al. 1997, Harazaki \& Isshiki 1998, Tortamano et al. 2009). Yet many diverse opinions existed concerning the duration of treatment, radiant power, frequency, and energy density.

\subsubsection{Tooth movement}

The biological control of tooth movement still has not well recognized. The most accepted theory of tooth movement is pressure-tension theory, which is based on stimulating cellular differentiation through chemical mediators. This theory states that force application causes tooth displacement within the PDL, which in turn results in compression in some areas of the PDL, while other parts may be stretched. In the compression side blood circulation is decreased, while in the tension side blood flow is maintained or even increased. The alteration in blood flow creates rapid changes in the proportion of oxygen and other metabolites within the PDL, which in turn can stimulate the release of other biologically active elements. These chemical alterations would stimulate cellular differentiation and cell activity.(Proffit et al., 2007) Prostaglandin E, Interleukin 1a and Interleukin $1 \beta$ are some of the important mediators released during the process of tooth movement. It is believed that orthodontic tooth movement includes many inflammation like reactions, because it is associated with high vascular activity, release of many leukocytes and macrophages, and involvement of the immune systems. This is important because it implies that the whole cascade of factors involved in an inflammation process may be part of the reactions to orthodontic forces in the tooth-supporting tissues.(Thilander et al., 2005)

Several studies have represented the effects of LLLT on orthodontic tooth movement. In five of nine animal studies about stimulation effects of LLLT on orthodontic tooth movement (Kawasaki and Shimizu 2000, Sun et al. 2001, Goulart et al. 2006, Yamaguchi M et al. 2007, Seifi et al. 2007, Fujita et al. 2008, Yoshida et al. 2009, Yamaguchi et al. 2010, Kim et al. 2010), experiments were performed on albino Wistar rats using the same laser device and the same parameters (Kawasaki and Shimizu 2000, Yamaguchi M et al. 2007, Fujita et al. 2008, Yoshida et al. 2009, Yamaguchi et al. 2010). Even though the energy density used in these studies was considerably higher $(54 \mathrm{~J}, 19.108 \mathrm{~J} / \mathrm{cm} 2)$ than it is thought to be appropriate for 
biostimulation $(2-12 \mathrm{~J} / \mathrm{cm} 2)$, it was concluded in all of the five studies that laser radiation had stimulated tooth movement. When the other animal studies were examined, it was noticed that there were differences about subject type, the energy dose given, and about the results. Seifi et al. (2007) reported the effects of two types of LLL wavelengths $(850 \mathrm{~nm}$ and $630 \mathrm{~nm}$ ) on orthodontic tooth movements in rabbits. The total amount of energy in $850 \mathrm{~nm}$ and $630 \mathrm{~nm}$ laser groups was $8.1 \mathrm{~J} / \mathrm{cm} 2$ and $27 \mathrm{~J} / \mathrm{cm} 2$, respectively. The authors showed that the amount of orthodontic tooth movement, after LLL application, was diminished, and there was no significant difference between the laser groups. Cruz et al. (2004), Youssef et al. (2008), and da Silva Sousa et al. (2011) demonstrated clinically that LLLT accelerates the orthodontic movement in humans. Cruz et al. (2004) conducted an experiment on 11 young patients who required tooth movement for extraction space closure. They were irradiated with LLLT of $780 \mathrm{~nm}$ wavelength (for $10 \mathrm{~s}$ at $20 \mathrm{~mW} ; 5 \mathrm{~J} / \mathrm{cm} 2$ ) on one side of the maxilla for 4 days in a month and were not irradiated on the opposite side, which acted as the control. The results showed that the experimental side demonstrated significantly more rapid progression of space closure than the control side. Youssef et al. (2008) evaluate the effect of the GaAlAs diode laser $(809 \mathrm{~nm}, 100 \mathrm{~mW})$ during an orthodontic movement in a group of 15 adult patients. They demonstrated that the velocity of canine movement was significantly greater in the lased group than in the control group. This was confirmed by da Silva Sousa et al. (2011) which used a diode laser $(780 \mathrm{~nm}, 20 \mathrm{~mW}, 10 \mathrm{sec}, 5 \mathrm{~J} / \mathrm{cm} 2)$ for 3 days. However, Limpanichkul et al. (2006) found no difference in tooth movement rate after application of LLL for 3 days in a month. They claimed that the energy capacity of LLL $(25 \mathrm{~J} / \mathrm{cm} 2)$ in their study was probably too low to produce stimulatory effects on orthodontic tooth movement. However, their LLL application method for orthodontic tooth movement was different from the others. They used a $0.09 \mathrm{~cm} 2$ spectral area to irradiate the alveolar mucosa at some point. This restricted application might be a lack for the whole periodontium surrounding the tooth.

Fujita et al. (2008) and Yamaguchi et al. (2007) reported that LLLT stimulated the velocity of tooth movement via RANK and c-Fms gene expressions in vitro. This was confirmed by Yamaguchi et al. (2010) which showed that LLLT accelerates the process of bone remodeling by stimulating MMP-9, cathepsin $\mathrm{K}$, and integrin subunits of a(v)b3 expression during orthodontic tooth movement in rats.

\subsubsection{Distraction osteogenesis}

Distraction osteogenesis is a method to induce new bone formation and investing soft tissue under the influence of tensional stress at osteotomized sites of a healing bone. Distraction osteogenesis not only induces bone formation but also results in formation of new soft tissue (histogenesis) over the new bone. This method was used successfully by Alizarow in the 1950s to lengthen the bony segments of the limbs, and now is widely used in dentistry for correcting deficient growth of the maxilla and mandible in patients with congenital problems such as cleft lip/palate and hemifacial microsomia. Distraction osteogenesis makes it possible to achieve a greater amount of bone lengthening than that achieved with conventional orthognathic surgery without the need for placing bone grafts. An additional advantage of this technique is that the correction can be performed at an earlier age. However, precise positioning of the jaw is not possible with this method, and consequently orthognathic surgery may be required later to achieve optimal treatment results. Distraction osteogenesis is a suitable option for extensive lengthening of the ramus in patients with 
moderately severe hemifacial microsomia, and also for advancing the mid face in patients having severe maxillary deficiency such as those with Crouzon syndrome. Furthermore, it is now possible to widen mandibular symphysis through distraction osteogenesis technique, a procedure that cannot be performed with orthognathic surgery due to the lack of soft tissue for covering the bone graft at that area.

Distraction osteogenesis consist of four sequential steps:(Cope and Samchukov, 2005) The first step is osteotomy, which provokes the process of bone repair at surgically created sites. The second stage is called latency, which defines the period between bone fracture and initiation of tensional stress to the bone. In latency period, a reparative callus is allowed to form. In the third stage or distraction phase, a gradual traction is applied to the bone to create new bone at the surgical sites. The bony segments are usually separated at a rate of 0.5-1.5 $\mathrm{mm}$ per day during the distraction phase. Consolidation is the fourth step of distraction osteogenesis defining the period between the end of traction application and removal of the distraction device. This stage is necessary to allow complete mineralization of the new bone formed by distraction process. Because of the time required for bone maturation and for removal of the distracter, distraction osteogenesis may generate discomfort, which has led some authors to study solutions to accelerate new bone formation (Hübler et al. 2010).

Miloro et al. (2007) evaluated the effect of LLLT during mandibular distraction osteogenesis and concluded that LLL accelerates the process of bone regeneration during the consolidation phase after distraction osteogenesis. Further, Kreisner et al. (2010) evaluated the action of LLLT on the percentage of newly formed bone in rabbit mandibles that underwent distraction osteogenesis. Infrared GaAlAs LLLT $(\lambda=830 \mathrm{~nm}, \mathrm{P}=40 \mathrm{~mW})$ was applied directly on the bone site that underwent distraction osteogenesis during bone consolidation at 48-hour intervals. The results suggested that the percentage of newly formed bone was greater in the LLLT group than in the control group. Cerqueira et al. (2007) stated that the laser has been more favorable when used in the consolidation period, after bone elongation. The results of a study by Hübler et al. (2010) showed that LLLT had a positive effect on the percentage of newly formed bone, on the chemical composition according to the Ca-to-P ratios, and on the crystallinity and crystalline structure at the distraction osteogenesis sites.

\subsubsection{Retention \& relapse}

Relapse after orthodontic correction of malocclusions is an undesirable but frequent experience for nearly all orthodontists. Teeth that have moved by orthodontic forces tend to return to their original positions, a phenomenon referred to as relapse. Generally, occlusion instability occurs because of the following reasons:

1. Changes related to growth: This type of relapse appears in long time and is usually related to continuation of growth in the original pattern caused malocclusion. An example is deepening of overbite due to growth or uncoordinated growth of maxilla and mandible in orthodontically treated patients. To counteract these changes, active treatment should be continued until growth is essentially complete.

2. Inherent instability of the occlusion due to soft tissue pressure: Alignment of the teeth in the dental arch is in equilibrium between the tongue pressure and labial/buccal soft tissue pressure. If there is any major imbalance between extra and intra oral soft tissue pressures, there would be a relapse tendency. For example widening of the mandibular 
arch, particularly in the canine area, is susceptible to relapse. The only solution to counteract relapse in these cases is to use permanent retention.

3. The changes related to fibrous system of PDL and gingival: These fibers may be responsible for most of the short term relapse after orthodontic treatment, for example after correction of rotated teeth and diastema closure. The elastic fibers of the gingival in particular may be stretched and displaced for long times after orthodontic correction, causing tooth movement forces even one year after appliance removal.

After appliance removal, the important stage of retention period is initiated. In this period, the orthodontist aims to retain the corrected tooth position passively, while the alveolar bone and gingival and periodontal fibers are remodeled. During the period of retention, the osteoid is replaced by bundle bone, which is finally changed to lamellated bone with harvesian system, and gingival and periodontal fibers are also reorganized.

LLLT effects on the relapse tendency of orthodontically rotated teeth have not been fully characterized. Kim et al. (2010) investigated the effectiveness of LLLT on orthodontically rotated teeth in beagles. A Ga-Al-As diode laser was used. The biostimulation mode (pulsed wave, $10 \mathrm{~Hz}, 763 \mathrm{~mW}, 4.63-6.47 \mathrm{~J} / \mathrm{cm} 2$ ) was used for irradiation, with the fiber tip held 2-3 $\mathrm{mm}$ away from the gingiva. The coronal and apical thirds of the roots were irradiated every 3 days for 30 seconds each for 4 weeks. They concluded that LLLT of orthodontically rotated teeth without retainers increased the rotational relapse of the teeth compared with the control group.

\subsubsection{Growth modification}

\section{Maxillary expansion}

Maxillary expansion may be required in patients who have deficient maxillary width. This treatment also helps to remove crowding and align the teeth. The mid-palatal suture is separated easily up to age nine or ten, therefore any expansion device is expected to produce a combination of dental and skeletal expansion. However, the midpalatal suture tend to interdigitate more and more with increasing age, and heavy forces are needed to microfracture it in adolescent patients. Usually a fixed type of jackscrew device is used to apply heavy forces to separate the suture, and either slow or rapid expansion protocols can be used for this purpose.

Saito and Shimizu (1997) studied the effects of LLLT on the expansion of midpalatal sutures in rats, comparing the bone regeneration obtained with and without laser treatment. Their results showed that the therapeutic effects of laser are dependent on the total dosage, the frequency, and the duration of the treatment. Their laser-irradiated group showed $20-40 \%$ better results when compared to the control group.

Mandibular growth

When mandible is deficient as is seen in most class II patients, growth modification is a suitable treatment option for growing children. To do this, a functional appliance is usually indicated to pull the condyle out of the glenoid fossa a sufficient distance for long durations, enhancing condylar growth amount and creating a more favorable growth direction in mandibular condyle. Growth modification for correcting mandibular deficiency can be performed successfully in late mixed dentition and early permanent dentition patients before the end of the adolescent growth spurt, but the chance of skeletal versus dental correction is reduced as the patient gets older. 
It was proposed that if LLLT increases bone and cartilage formation, the treatment might be easier and more stable. In 2010 Seifi et al. investigated the effects of low level GaAs diode laser $(\lambda=904 \mathrm{~nm}, 2,000 \mathrm{~Hz}$, pulse length $200 \mathrm{~ns}$ and output power $4 \mathrm{~mW})$ on chondroblastic and osteoblastic activity of condyles in rats. Laser irradiation was performed either bilaterally or on the right condyle. They showed that LLLT had a significant effect on the increase of mandibular length in rats and might be helpful in the correction of class II malocclusions. However, further studies are required to confirm these results.

\section{Conclusion}

To have a precise diagnosis and to select a proper and successful laser-assisted treatment modality for a disease, the clinician should have a comprehensive understanding of the principles and fundamentals of laser and its helpful abilities. When considering the use of lasers in clinical dentistry, the practitioner must use clinical experience, receive proper training, and have familiarity with the operating characteristics of each device. Because of the variable composition of human tissue and the differing ways in which laser energies are absorbed, no single laser is appropriate for all dental applications.

\section{References}

Abalos, C., Herrera, M., Jimenez-Planas, A., \& Llamas,R. (2009). Performance of laser fluorescence for detection of occlusal dentinal caries lesions in permanent molars: an in vivo study with total validation of the sample. Caries Research, vol. 43, no. 2, pp. 137-141

Abdul-Kader, HM.,\& Ibrahim, SA. (1999).A comparative study of CO2 laser debonding of three types of ceramic brackets. Al-Azhar J Dent Sci, 2:91-97

Ahrari, F., Heravi, F., Fekrazad, R., Farzanegan F,\& Nakhaee S. Does ultra pulse CO2 laser reduce the risk of enamel damage during debonding of ceramic brackets? Laser Med Sci,(In press).

Akarsu, S.,\& Koprulu, H. (2006). In vivo comparison of the efficacy of DIAGNOdent by visual inspection and radiographic diagnostic techniques in the diagnosis of occlusal caries. Journal of Clinical Dentistry, vol. 17, no. 3, pp. 53-58

Akova, T., Yoldas, O., Toroglu, MS.,\& Uysal, H .(2005). Porcelain surface treatment by laser for bracket-porcelain bonding. Am J Orthod Dentofacial Orthop, 128(5):630-637

Alcaniz, M., Grau, V., Monserrat, C., Juan, C.,\& Albalat, S.(1999). A system for the simulation and planning of orthodontic treatment using a low cost 3D laser scanner for dental anatomy capturing. Studies in Health Technology and Information,62:8-14.

Alencar, CJ., Braga, MM., de Oliveira, E., Nicolau, J.,\& Mendes, FM. (2009). Dye-enhanced laser fluorescence detection of caries lesions around brackets. Lasers Med Sci 24(6):865-70.

Aljehani, A., Bamzahim, M., Yousif, A., \& Shi, X. Q. (2006). In vivo reliability of an infrared fluorescence method for quantification of carious lesions in orthodontic patients. Oral Health \& Preventive Dentistry, vol. 4, no. 2, pp. 145-150

Aljehani, A., Tranaeus, S., Forsberg CM, Angmar-Månsson B, Shi XQ (2004) In vitro quantification of white spot enamel lesions adjacent to fixed orthodontic appliances using quantitative light induced fluorescence and DIAGNOdent. Acta Odontol Scand ,62:313-318 
Al-Omiri, MK., \&Abu Alhaija, ES. (2006). Factors affecting patient satisfaction after orthodontic treatment. Angle Orthod ,76(3): 422-431.

Anderson, A., Skold-Larsson, K. , Hallgren, A., Petersson, LG. , \& Twetman, S.(2007) .Effect of a dental cream containing amorphous cream phosphate complexes on white spot lesion regression assessed by laser fluorescence. Oral Health $\mathcal{E}$ Preventive Dentistry, vol. 5, no. 3, pp. 229-233

Anderson, AM., Kao, E., Gladwin, M., Benli, O., Ngan, P.(2002). The effects of argon laser irradiation on enamel decalcification: An in vivo study. Am J Orthod Dentofacial Orthop, 122(3), 251-259.

Aoki, A., Sasaki, K. M., Watanabe, H., Ishikawa, I. (2004) .Laser in nonsurgical periodontal therapy. Periodontal 2000 ,36, 59-97.

Angnes, V., Angnes, G. , Batisttella, M., Grande, RHM., Loguercio, AD.,\& Reis, A. (2005). Clinical effectiveness of laser fluorescence, visual inspection and radiography in the detection of occlusal caries.Caries Research, vol. 39, no. 6, pp. 490-495

Anic, I., Pavelic, B., Peric, B.,\& Matsumoto, K. (1996).In vitro pulp chamber temperature rises associated with the argon laser polymerization of composite resin. Lasers Surg Med,19:438-44.

Anttonen, V., Seppa, L., \& Hausen, H. A follow-up study of the use of DIAGNOdent for monitoring fissure caries in children. Community Dentistry and Oral Epidemiology, vol. 32, no. 4, pp. 312-318, 2004.

Ariyaratnam, MT., Wilson, MA., Blinkhorn, AS. (1999). An analysis of surface roughness, surface morphology and composite/dentin bond strength of human dentin following the application of the Nd:YAG laser. Dent Mater, 15:222-228

Ariyaratnam, MT., Wilson, MA., Mackie, IC., Blinkhorn, AS .(1997). A comparison of surface roughness and composite/enamel bond strength of human enamel following the application of the Nd:YAG laser and etching with phosphoric acid. Dent Mater ,13:51-55

Arridge, S., Moss, JP., Linney, AD., \& James, DR. (1985).Three dimensional digitization of the face and skull. J Maxillofac Surg, Jun; 13(3): 136-43.

Artun , J. (1997). A post-treatment evaluation of multibonded ceramic brackets in orthodontics. Eur J Orthod ,19(2): 219-228.

Ashmore, JL, Kurland BF, King GJ, Wheeler TT, Ghafari J,\& Ramsay DS. (2002).A 3dimensional analysis of molar movement during headgear treatment. Am J Orthod Dentofacial Orthop,121:18-29.

Asquith J, Gillgrass T, Mossey P.( 2007)Three-dimensional imaging of orthodontic models: a pilot study. Eur J Orthod. 2007 Oct;29(5):517-22.

Astvaldsdottir A, W. P. Holbrook, and S. Tranaeus, "Consistency of DIAGNOdent instruments for clinical assessment of fissure caries," Acta Odontologica Scandinavica, vol. 62, no. 4, pp. 193-198, 2004.

Anusavice, KJ. (2003). Philips' Science of dental materials. $11^{\text {th }}$ ed. St. Louis: Saunders Co: 616,617 .

Ayoub AF, D. Wray, K.F. Moos, P. Siebert, J. Jin and T.B. Niblett et al., (1996)Threedimensional modeling for modern diagnosis and planning in maxillofacial surgery, Int J Adult Orthod Orthog Surg vol: 11, pp. 225-233. 
Ayoub, AF., Siebert, P., Moos, KF., Wray, D., Urquhart, C., \& Niblett, T.B. (1998). A visionbased three-dimensional capture system for maxillofacial assessment and surgical planning, Br J Oral Maxillofac Surg, 36: pp. 353-357.

Azzeh, E.,\& Feldon, PJ. (2003).Laser debonding of ceramic brackets: a comprehensive review. Am J Orthod Dentofacial Orthop, 123:79-83.

Babacan, H., Doruk, C., Bicakci, AA.(2010) .Pulpal blood flow changes due to rapid maxillary expansion. Angle Orthod, Nov;80(6):1136-40.

Bader, JD.,\& Shugars,DA. (2004).A systematic review of the performance of a laser fluorescence device for detecting caries,Journal of the American Dental Association, vol. 135, no. 10, pp. 1413-1426

Baker,SS., Hunnewell JM. Muenzler WS.,\&Hunter,GJ. (2002).Laser blepharoplasty: diamond laser scalpel compared to the free beam CO2 laser. Dermatol Surg ,28, pp. 127-131.

Bamzahim, M. ,Aljehani, A.,\& Shi XQ., (2005).Clinical performance of DIAGNOdent in the detection of secondary carious lesions, Acta Odontologica Scandinavica, vol. 63, no. 1, pp. 26-30

Barghi, N., Berry, T., Hatton, C. (1994). Evaluating intensity output of curing lights in private dental offices. J Am Dent Assoc ,125(7): 992-996.

Barwick, PJ.,\& Ramsay, DS. (1996).Effect of brief intrusive force on human pulpal blood flow. Am J Orthod Dentofacial Orthop,110:273-279.

Basaran, G., Ozer, T., Berk, N.,\& Hamamci, O. (2007). Etching enamel for orthodontics with an erbium, chromium:yttrium-scandiumgallium-garnet laser system. Angle Orthod, 77:117-124

Benham, AW., Campbell, PM., Buschang, PH .(2009). Effectiveness of pit and fissure sealants in reducing white spot lesions during orthodontic treatment. A pilot study. Angle Orthod, 79(2):338-45.

Bertrand, C., le Petitcorps Y, Albing re L, Dupuis V. (2004).Optimization of operator and physical parameters for laser welding of dental materials. British Dental Journal ,196:413-418.

Bird, SE., Williams, K,\& Kula K.( 2007). Preoperative acetaminophen vs ibuprofen for control of pain after orthodontic separator placement. Am J Orthod Dentofacial Orthop ,132(4): 504-510.

Bock, JJ., Fraenzel ,W., Bailly J, Gernhardt CR, \& Fuhrmann RA. (2008). Influence of different brazing and welding methods on tensile strength and microhardness of orthodontic stainless steel wire. Eur J Orthod. Aug;30(4):396-400.

Bihari, J., Mester, A. (1989) The biostimulative effect of low level laser therpy of long standing crural ulcer using helium neon laser, helium neon plus infrared lasers and nocoherent light: Preliminary report of a randomized double- blind comparative study. Laser Therapy, 1[2], 97-102.

Biordal, J. M. (2006). Can a Cochrane review in controversial areas be biased? A sensitivity analysis based on the protocol of a systematic Cochrane review low level Laser Therapy in Osteorthritis. Photomed Laser Surg ,23(5), 453-458.

Biordal, J, M., Couppe, C., Chow, R.T., Turner, J., Liunggren, A. E. (2003). A systematic review of low level lasertherapy with location - specific doses for pain from chronic joint disorders. Australian J Physiother, 49, 107-116. 
Bjordal, J. M., Couppe, C., Liunggren, A. (2001) Low level laser therapy for tendinopathies. Evidence of a dose - response pattern. Physical Therapy Reviews, 6(2), 91-100.

Bjordal, J.M., Greve, G. (1998) What may alter the conclusions of reviews ? Physical Therapy Reviews,3 , 121- 132.

Boloognani, L., Volpi, N.(1992) Low- Power Laser- Enzyme Interaction. Published Proceedings of the $3^{\text {rd }}$ World Congress of International Soc, for Low Power Laser Application in Medicine and Surgery. Ed. Galetti, G,. 213-222. Monduzzi Editore.

Bishara, SE., Ostby, AW., Laffoon, J, \& Warren, JJ. (2008). Enamel cracks and ceramic bracket failure during debonding in vitro. Angle Orthod ,78(6): 1078-1083.

Bishara SE, Trulove TS. 1990a. Comparisons of different debonding techniques for ceramic brackets: an in vitro study. Part II. Findings and clinical implications. Am J Orthod Dentofacial Orthop 98(3): 263-273.

Brouns EM, Schopf PM, Kocjancic B. 1993. Electrothermal debonding of ceramic brackets. An in vitro study. Eur J Orthod 15(2): 115-123.

Bishara SE, Trulove TS. 1990b. Comparisons of different debonding techniques for ceramic brackets: an in vitro study. Part I. Background and methods. Am J Orthod Dentofacial Orthop 98(2): 145-153.

Bradley P, Tuner J.(2007).Laser Phototherapy in Dentistry, In: Proceedings of the $1^{\text {st }}$ International Workshop of Evidence Based Dentistry on Lasers in Dentistry, Gutknecht N, pp.(149-171),Quintessence publisher,ISBN:978-1-85097-167-2,Berlin

Bradley, P. (2005) .Abstracts of North American Association of Laser Therapy Conference $4 / 14$.

Brouns, EM., Schopf, PM., \& Kocjancic, B. (1993). Electrothermal debonding of ceramic brackets. An in vitro study. Eur J Orthod ,15(2): 115-123.

Brodin, P., Linge L,\& Aars, H. (1996).Instant assessment of pulpal blood flow after orthodontic force application. J Orofac Orthop, 57: 306-309. Cacciafesta, V., Sfondrini, MF., Barina, E., Scribante, A., Garino, F,\& Klersy, C.( 2005). Effect of different light sources and guides on shear bond strength of brackets bonded with 2 adhesive systems. Am J Orthod Dentofacial Orthop ,128(1): 99-102.

Canay, S., Kocadereli ,I., \& Ak"ca, E. (2000). The effect of enamel air abrasion on the retention of bonded metallic orthodontic brackets. Am J Orthod Dentofacial Orthop ,117(1): 15-19.

Carvalho, Fde A, Almeida RC, Almeida MA, Cevidanes LH, Leite MC.( 2010). Efficiency of light-emitting diode and halogen units in reducing residual monomers. Am J Orthod Dentofacial Orthop ,138(5): 617-622.

Cerqueira, A., Silveira, RL., Oliveira, MG., Sant'ana Filho, M.,\& Heitz, C. (2007).Bone tissue microscopic findings related to the use of diode laser $(830 \mathrm{~nm})$ in ovine mandible submitted to distraction osteogenesis. Acta Cir. Bras, Vol 22 (2)

Cha, BK., Lee, JY., Jost-Brinkmann, PG.,\& Yoshida, N.(2007) Analysis of tooth movement in extraction cases using three-dimensional reverse engineering technology. Eur J Orthod, 29:325-331.

Chai, T., \& Chou, CK. (1998). Mechanical properties of laser-welded cast titanium joints under different conditions . Journal of Prosthetic Dentistry , $79: 477$ - 483

Chandra, S., Chandra, S., Chandra, R. (2000). A textbook of dental materials with multiple choice questions. $1^{\text {st }}$ ed. New Delhi: Jaypee brothers medical publishers: 326. 
Chen ,HY., Su MZ., Chang HF, Chen YJ, Lan WH, Lin CP.( 2007). Effects of different debonding techniques on the debonding forces and failure modes of ceramic brackets in simulated clinical set-ups. Am J Orthod Dentofacial Orthop ,132(5): 680686.

Chu, CH., Lo, ECM., \& You, DSH.(2009) Clinical diagnosis of fissure caries with conventional and laser-induced fluorescence techniques. Lasers in Medical Science, pp. 1-8

Cilesiz ,I. (2004).Laser-Tissue Interaction. Marcel Dekker, Inc., ISBN: 0-8247-4258-3, New York, NY, USA

Cobb, DS., Dederich, DN., \& Gardner TV. (2000) In vitro temperature change at the dentin/pulpal interface by using conventional visible light versus argon laser. Lasers Surg Med, 26:386-97.

Combe, EC. (1981). Notes on dental materials. $4^{\text {th }}$ ed. Edinburgh: Churchill Livingstone: 271.

Cook, PA., Youngson, CC. (1988). An in vitro study of the bond strength of a glass ionomer cement in the direct bonding of orthodontic brackets. Br J Orthod 15(4): 247-253.

Cope, JB.,\& Samchukov, ML. Craniofacial distraction osteogenesis: Basic principles and clinical applications. In: Graber TM, Vanarsdall RL, Vig KWL. Orthodontics: Current principles \& techniques. $4^{\text {th }}$ ed. St. Louis: Mosby: 1058-1061.

Cruz, DR., Kohara, EK., Ribeiro, MS., \&Wetter NU. (2004). Effects of low-intensity laser therapy on the orthodontic movement velocity of human teeth: a preliminary study. Lasers Surg Med ,35: 117-120

Da Silva Sousa, MV., Scanavini, MA., Sannomiya, EK., Velasco, LG.,\& Angelieri, F. (2011) Influence of low-level laser on the speed of orthodontic movement. Photomed Laser Surg, Mar;29(3):191-6. Epub Jan 23.

Dubroc, GC., Jr., Mayo JA, Rankine CA.( 1994). Reduction of caries and of demineralization around orthodontic brackets: effect of a fluoride-releasing resin in the rat model. Am J Orthod Dentofacial Orthop ,106(6): 583-587.

Duncan, Y., Powell GL, Higuchi WI, Fox J. (1993)Enhancement of argon laser effect on dissolution and loss of human enamel. J Clin Laser Med Surg; 11: 259-261.

Dunn ,WJ., \& Taloumis LJ. (2002). Polymerization of orthodontic resin cement with lightemitting diode curing units. Am J Orthod Dentofacial Orthop ,122(3): 236-241.

Dyson, M. (2005). Abstracts of North American Association of Laser Therapy Conference 14.

Einstein ,A.( 1905). Uber einen die Erzeugung und Verwandlung des Lichtes betreffenden heuristischen Gesichtspunkt. Annalen der physik 17:132

Einstein, A. (1917).Zur quantentheorie der strahlung. Physikalische Z 18:121-128,1917

Elaut, J., \& Wehrbein, H. (2004).The effects of argon laser curing of a resin adhesive on bracket retention and enamel decalcification: a prospective clinical trial. Eur J Orthod;26:553-60.

Eliades, T. (2007). Orthodontic materials research and applications: part 2. Current status and projected future developments in materials and biocompatibility. Am J Orthod Dentofacial Orthop, 131(2): 253-262.

Elvebak, BS., Rossouw, PE., Miller, BH., Buschang, P.,\& Ceen, R. (2006). Orthodontic bonding with varying curing time and light power using an argon laser. Angle Orthod ,76:837-844 
Emshoff, R., Kranewitter R., Brunold S, Laimer K, \&Norer, B. (2008) Characteristics of pulpal blood flow levels associated with non-segmented and segmented Le Fort I osteotomy. Oral Surg Oral Med Oral Pathol Oral Radiol Endod, 105: 379-384.

Emshoff, R., Kranewitter, R., Gerhard S, Norer B, Hell, B. (2000). Effect of segmental Le Fort I osteotomy on maxillary tooth type related pulpal blood flow characteristics. Oral Surg Oral Med Oral Pathol Oral Radiol Endod, 89: 749-752.

Ferracane, JL. (2001). Materials in dentistry: principles and applications. 2nd ed. Philadelphia: Lippincott Williams \& Wilkins: 288.

Firestone, AR., Wheatley AM,\& Thu"er, UW. (1997).Measurement of blood perfusion in the dental pulp with laser Doppler flowmetry. Int J Microcirc,17: 298-304.

Flaitz, CM., Hicks, MJ.,\& Westerman, GH. (1995).Argon laser irradiation and acidulated phosphate fluoride treatment in caries-like lesion formation in enamel: an in-vitro study. Pediatr Dent, 17: 31-39.

Fornaini, C., Passaretti, F., Villa, E., Rocca, JP., Merigo, E,\& Vescovi, P. (2010). Intraoral laser welding: ultrastructural and mechanical analysis to compare laboratory laser and dental laser. Lasers Med Sci.

Fox, JL., Duncan, Y.,\& Otsuka, M. (1992).Initial dissolution rate studies on dental enamel after $\mathrm{CO}_{2}$ laser irradiation. J Dent Res ,71: 1390-1398.

Fox, NA., McCabe, JF.,\& Gordon, PH. (1991). Bond strengths of orthodontic bonding materials: an in-vitro study. Br J Orthod ,18(2): 125-130.

Fuhrmann, R., Gutknecht, N., Magunski, A.,Lampert, F.,\& Diedrich, P. (2001). Conditioning of enamel with Nd:YAG and CO2 dental laser systems and with phosphoric acid. An in-vitro comparison of the tensile bond strength and the morphology of the enamel surface. J Orofac Orthop.Sep;62(5):375-86.

Fujita, S., Yamaguchi, M., Utsunomiya T, Yamamoto, H.,\& Kasai, K.(2008). Low-energy laser stimulates tooth movement velocity via expression of RANK and RANKL. Orthod Craniofac Res , 11:143-155

Gazelius, B., Olgart, L., Edwall, B.,\& Edwall, L. (1986).Non-invasive recording of blood flow in human dental pulp. Endod Dent Traumatol ,2:219-21.

Geiger ,AM., Gorelick, L., Gwinnett, AJ.,\& Benson, BJ.( 1992). Reducing white spot lesions in orthodontic populations with fluoride rinsing. Am J Orthod Dentofacial Orthop, 101(5): 403-407

Geusic, J.E. (1966) The continuous Nd: YAG laser . IEEE J Quant Electron ,2(4), 105

Geusic, J. E., Marcos, H.M., \& Van Uitert, L. G. (1964). Laser Dscillations in Nd- doped yttrium alum aluminium, yttrium gallium and gadolinium garnets. Appl Phys Lett ,4 (101), 182-184.

Goldman, L., Ingelman, JM., \& Richfield, DF. (1964).Impact of the laser on nevi and melanomas. Arch Dermatol , 90: 71-75.

Gomi, A., Kamiya, K., Yamashita, H., Ban Y., Senda. A., Hara, G., Yamaguchi, M., Narita. Te.,\& Hasegaw, J. (1989). A clinical study on the soft laser 632 a He Ne Low energy medical laser . 2 nd laser. 2 nd report: The effect in relieving the pain of hypersensitive dentin and the pain during seating an inlay. Aichi Gakuin Daigaku Shigakkai Shi, 24 (3), 890-399.

Goodman, BD., \& Kaufman, HW.( 1977).Effects of an argon laser on the crystalline properties and rate of dissolution in acid of tooth enamel in the presence of sodium fluoride. J Dent Res; 56: 1201-1207. 
Gordon, E. I., Labuda, E.F., \& Bridges, W.B. (1964). Continuous visible laser action in singly ionized argon, Krypton and exenon. Appl Opt Lett ,4(10) , 178.

Gorelick, L., Geiger, AM., \& Gwinnett, AJ. (1982). Incidence of white spot formation after bonding and banding. Am J Orthod ,81(2): 93-98.

Gostanian, HV., Z. Shey C. ,Kasinathan, J. Caceda, \& Janal, M. N. (2006). An in vitro evaluation of the effect of sealant characteristics on laser fluorescence for caries detection, Pediatric Dentistry, vol. 28, no. 5, pp. 445-450

Goulart, CS., Nouer, PRA, Mouramartins, L., Garbin, IU.,\& Lizarelli RDZ .(2006). Photoradiation and orthodontic movement: experimental study with canines. Photomed Laser Surg, 242:192-196

Hall, A., \& Girkin, J. M. (2004). A review of potential new diagnostic modalities for caries lesions. J Dent Res, 83 (Spec Iss C), C89-C94.

Hall, R. N., Fenner, G.E., Kingsley, J.D., Soltys, T.J.,\& Carlson, R. O. (1962) Coherent light emission from GaAs junctions. Phys Rev Lett ,9(9). 366.

Hamblin, MR.,\& Demidova, T.(2006).Mechanisms for Low Level Light Therapy, Proc. of the SPIE ,Vol.6140-614001.PP:1-12

Harada, K., Sato, M.,\& Omura, K. (2004) Bloodflow and neurosensory changes in the maxillary dental pulp after differing Le Fort I osteotomies. Oral Surg Oral Med Oral Pathol Oral Radiol Endod ,97: 12-17

Harazaki, M.,\& Isshiki Y. (1998). Soft laser irradiation effects on pain reduction in orthodontic treatment. Bull Tokyo Dent Coll, 39: 95-101.

Harazaki M, Takahashi H, Isshiki Y. (1997). Soft laser irradiation induced pain reduction in orthodontic treatment. Bull Tokyo Dent Coll,38:291-5.

Hayakawa, K. (2005). Nd:YAG laser for debonding ceramic orthodontic brackets. Am J Orthod Dentofacial Orthop, 128:638-647

Hayashi, K., Araki, Y., Uechi, J., Ohno, H., \& Mizoguchi, I. .(2002).A novel method for the three-dimensional (3-D) analysis of orthodontic tooth movement-calculation of rotation about and translation along the finite helical axis. J Biomech, 35(1):45-51.

Hayashi, K., Uechi, J., Murata, M.,\& Mizoguchi, I. (2004).Comparison of maxillary canine retraction with sliding mechanics and a retraction spring: a three-dimensional analysis based on a midpalatal orthodontic implant. Eur J Orthod, 26:585-589.

Haytac, MC.\& Ozcelik, O.(2006). Evaluation of patient perceptions after frenectomy operations: a comparison of carbon dioxide laser and scalpel techniques. J Periodontol, 77(11), pp. 1815-1819.

Hibst, R.,\& Gall,R. (1998). Development of a diode laser-based fluorescence caries detector. Caries Research, vol. 32, no. 4, article 294

Hibst ,R.,\& Keller, U.(1989). Experimental studies of the application of the Er YAG laser on dental hard substances: 1. Measurement of ablation rate. Lasers Surg Med , 9: 338344.

Hicks, MJ., Flaitz, CM.,\& Westerman GH. (1994) Argon laser irradiation in root surface caries: in vitro study examines laser's effects. J Am Dent Assoc, 125: 401-407.

Hicks, MJ., Flaitz, CM., \&Westerman, GH. (1993) Caries-like lesion initiation and progression in sound enamel following argon laser irradiation: an in-vitro study.ASDC J Dent Child, 60(3): 201-206. 
Hicks, MJ., Flaitz, CM.,\& Westerman, GH. .(1995).Enamel caries initiation and progression following low fluence (energy) argon laser and fluoride treatment. J Clin Pediatr Dent , 20: 9-13.

Hicks MJ, Flaitz CM,\& Westerman GH. (1997).Roots caries in-vitro after low fluence argon laser and fluoride treatment. Compend contin educ dent, 18: 543-552.

Hicks, J., Winn, D.II, Flaitz, C., \& Powell , L. (2004). In vivo caries formation in enamel following argon laser irradiation and combined fluoride and argon laser treatment: A clinical pilot study. Quintessence Int ,35(1), 15-20.

Hildebrand ,NK., Raboud, DW., Heo G, Nelson AE,\& Major, PW. (2007).Argon laser vs conventional visible light-cured orthodontic bracket bonding: an in-vivo and invitro study. Am J Orthod Dentofacial Orthop. Apr;131(4):530-6.

Hirogaki, Y., Sohmura, T., Satoh, H., Takahashi, J., \& Takada, K.( 2001).Complete 3-D reconstruction of dental cast shape using perceptual grouping. IEEE Trans Med Imaging, 20:1093-1101.

Hodgson, N., \& Weber, H. (1997). Optical resonators. Ch. 3/3 1.1., P.102. Springer- Verlag, New York.

Holonyak Jr., N.,\& Bevacqua. S. F. (1962). Coherent (visible) light emission form Ga (As1-x $\mathrm{P}_{\mathrm{x}}$ ) junctions. Appl Phys Lett, 1(4), 82-83.

Hossain M, Kimura Y, Nakamura Y, Yamada Y, Kinoshita JI, \& Matsumoto K. (2001).A study on acquired acid resistance of enamel and dentin irradiated by Er,Cr:YSGG laser. J Clin Laser Med Surg;19:159-63.

Hossain M, Nakamura Y, Yamada Y, Kimura Y, Matsumoto N, \& Matsumoto K. (1999). Effects of Er,Cr:YSGG laser irradiation in human enamel and dentin: ablation and morphological studies. J Clin Laser Med Surg. ,17(4):155-9.

Huang, YY., Chen, AC., Carroll JD, \& Hamblin, MR.(2009). Biphasic dose response in low level light therapy, Dose Response. Sep 1;7(4):358-83

Hübler, R., Blando, E., Gaião, L., Kreisner, PE., Post, LK., Xavier, CB.,\& de Oliveira MG.(2010). Effects of low-level laser therapy on bone formed after distraction osteogenesis. Lasers Med Sci. Mar;25(2):213-9.

Huth, KC., Neuhaus,KW., Gygax,M. Clinical performance of a new laser fluorescence device for detection of occlusal caries lesions in permanent molars. Journal of Dentistry, vol. 36, no. 12, pp. 1033-1040, 2008.

Gwinnett, AJ.( 1988). A comparison of shear bond strengths of metal and ceramic brackets. Am J Orthod Dentofacial Orthop ,93(4): 346-348.

Iijima, M., Yasuda, Y., Muguruma, T., Mizoguchi ,I.(2010). Effects of CO2 laser debonding of a ceramic bracket on the mechanical properties of enamel. Angle Orthod,Nov;80(6):1029-35.

Ikawa M, Fujiwara M, Horiuchi H, Shimauchi H. (2001).The effect of short-term tooth intrusion on human pulpal blood flow measured by laser Doppler flowmetry. Arch Oral Biol, 46: 781-787.

Inberg ,A., Oksman, M., Ben-David M,\& Croitoru N. (1998).Hollow waveguide for mid and thermal infrared radiation. J Clin Laser Med Surg ,16: 127-133.

Ip, TB., \&Rock, WP.( 2004). A comparison of three light curing units for bonding adhesive pre-coated brackets. J Orthod ,31(3): 243-247; discussion 202-243. 
Ismail SF, J.P. Moss and R. Hennessy. (2002). Three-dimensional assessment of the effects of extraction and nonextraction orthodontic treatment on the face. Am J Orthod Dentofacial Orthop ,121: 244-256.

Iwasaki K , Ohkawa S , Rosca I D , Uo M , Akasaka T , Watari F (2004) Distortion of laser welded titanium plates. Dental Materials Journal, 23 : 593 - 599

Jaberi ansari Z, Fekrazad R, Younessian F, AM Kalhori K, Gutknecht N. The effect of Er,Cr:YSGG laser on microshear bond strength of composite to enamel and dentin of human permanent teeth. Lasers Med Sci, (in press)

James JW, Miller BH, English JD, Tadlock LP, Buschang PH.( 2003) Effects of high-speed curing devices on shearbond strength and microleakage of orthodontic brackets. Am J Orthod Dentofacial Orthop, 123:555-61.

Jang, I., Tanaka, M., Koga, Y., Iijima, S., Yozgatian JH, Cha, BK.\& Yoshida, N. (2009). A novel method for the assessment of three-dimensional tooth movement during orthodontic treatment. Angle Orthod, May;79(3):447-53.

Javan, A., Bennett Jr., W.R.,\& Herriott, D.R. (1961). Population inversion and continuous optical maser oscillation in a gas discharge containing a He-Ne mixture. Phys Rev Let ,6(3). 106- 110.

Ji Y, Zhang F, Schwartz J, Stile F, Lineaweaver WC. (2002).Assessment of facial tissue expansion with three dimensional digitizer scanning. J Craniofac Surg, 13: 687-92.

Jones, SP., Gledhill, JR.,\& Davies, EH. (1999). The crystal growth technique--a laboratory evaluation of bond strengths. Eur J Orthod ,21(1): 89-93.

Jost-Brinkmann, PG., Stein H, Miethke RR, \&Nakata, M. (1992). Histologic investigation of the human pulp after thermodebonding of metal and ceramic brackets. Am J Orthod Dentofacial Orthop ,102(5): 410-417.

Kafas, P., Stavrianos, C., Jerjes, W., Upile, T., Vourvachis, M., Theodoridis, M.\& Stavrianou, I. (2009). Upper-lip laser frenectomy without infiltrated anaesthesia in a paediatric patient: a case report. Cases J. May 20;2:7138.

Kara, C. (2008).Evaluation of patient perceptions of frenectomy: a comparison of Nd:YAG laser and conventional techniques. Photomed Laser Surg.Apr;26(2):147-52.

Karu, T. (2003) Low power laser therapy . In: Biomedical Photonics Handbook. Chapter 48 and references therein. CRC Press- Taylor \& Francis.

Karu, T.(2000) Mechanisms of Low Power Laser Action on a Cellular. Level .Lasers in Medicine and Dentistry, Ed. Simunovic, Z, 97-125.

Karu, T. (2007). Ten Lectures on Basic Science of Laser Phototherapy . Prima Books, Grangesberg.

Kato, J., Wijeyeweera, RL.(2007) The effect of CO2 laser irradiation on oral soft tissue problems in children in Sri Lanka. Photomed Laser Surg. 25:264-268.

Katoh, H., Chen, RC., Chai, CT., Saito S, Yamasaki K,\& Shibasaki, Y. (1997)Effect of far infrared rays radiation on pain reaction associated with orthodontic tooth movement. J Japan Orthod, Soc 56: 17-25.

Kau, CH.(2005) . Reliability of measuring facial morphology with a 3-dimensional laser scanning system. American Journal of Orthodontics and Dentofacial Orthopedics ,128: 424-430.

Kau, CH., Knox, J., Zhurov, AI.,\& Richmond, S.( 2004 )Validity and reliability of a portable 3D optical scanning device for field studies. In: Proceedings of the 7th European 
Craniofacial Congress. Bologna: Monduzzi Editore-International Proceedings Division, (in press).

Kawasaki, K.,\& Shimizu, N. (2000). Effects of low-energy laser irradiation on bone remodeling during experimental tooth movement in rats. Lasers in Surgery and Medicine ,26: 282-291

Kelsey, WP., Blankenau, RJ., Powell, GL., Barkmeier, WW., Cavel, WT.,\& Whisenant BK.(1989) Enhancement of physical properties of resin restorative materials by laser polymerization. Lasers Surg Med , 9:623-7.

Khalife, MA, J. R. Boynton, J. B. Dennison, Yaman,P. \& Hamilton,JC.(2009).In vivo evaluation of DIAGNOdent for the occlusal dental caries.Operative Dentistry, 34( 2), pp. 136-141.

Khambay, B., Nebel, JC. Bowman, J. , Walker, F.,Hadley DM. \& Ayoub. (2002) 3D stereophotogrammetric image superimposition onto 3D CT scan images: the future of orthognathic surgery. A pilot study, Int J Adult Orthod Orthog Surg 17: 331-341.

Kim, JH., Kwon OW, Kim HI, Kwon YH.(2006). Acid resistance of erbium-doped yttrium aluminum garnet laser-treated and phosphoric acid-etched enamels. Angle Orthod, 76: 441-445.

Kim JH, Kwon OW, Kim HI, Kwon YH.(2005). Effectiveness of an Er:YAG laser in etching the enamel surface for orthodontic bracket retention. Dent Mater J. Dec;24(4):596602.

Kim JT, Cho SA .(2009). The effects of laser etching on shear bond strength at the titaniumceramic interface. J ProsthetDent 101:101-106

Kim SJ, Paek JH, Park KH, Kang SG, Park YG. Laser-aided circumferential supracrestal fiberotomy and low-level laser therapy effects on relapse of rotated teeth in beagles. Angle Orthod. 2010 Mar;80(2):385-90.

Kim SJ, Paek JH, Park KH, Kang SG, Park YG.(2010). Laser-aided circumferential supracrestal fiberotomy and low-level laser therapy effects on relapse of rotated teeth in beagles. Angle Orthod,Mar;80(2):385-90.

Kim YD, Kim SS, Kim SJ, Kwon DW, Jeon ES, Son WS .(2010). Low-level laser irradiation facilitates fibronectin and collagen type I turnover during tooth movement in rats. Lasers Med Sci ,25: 25-31

Kim YO, Park SB, Son WS, Ko CC, García-Godoy F, Kim HI,\& Kwon YH.( 2010 )Diodepumped solid-state laser for bonding orthodontic brackets: effect of light intensity and light-curing time. Lasers Med Sci. Jun 8. [Epub ahead of print]

Kimura, Y., Wilder-Smith, P., \& Matsumoto, K. (2000) Lasers in endodontics: A review. Int Endod J;33:173-85.

Klein, AL., Rodrigues LK, Eduardo CP, Nobre dos Santos M,\& Cury, JA. (2005).Caries inhibition around composite restorations by pulsed carbon dioxide laser application. Eur J Oral Sci;113: 239-44.

Klockowski, R., Davis, EL., Joynt RB, Wieczkowski G, Jr., \&MacDonald, A. ( 1989). Bond strength and durability of glass ionomer cements used as bonding agents in the placement of orthodontic brackets. Am J Orthod Dentofacial Orthop ,96(1): 60-64.

Kobayashi Y, Takagi H, Sakay H, Hashimoto F, Mataki S, Kobayashi K, Kato Y (1998). Effects of local administration of osteocalcin on experimental tooth movement. Angle Orthod 68: 259-266. 
Konig, K., Flemming G,\& Hibst R. (1998) .Laser-induced autofluorescence spectroscopy of dental caries. Cell Mol Biol (Noisy-legrand), 44:1293-1300

Konorov, S O., Mitrokhin, V P., Fedotov, A.(2004) .Hollow-core photonic-crystal fibres for laser dentistry. Phys Med Biol , 49: 1359-1368.

Konno, Y., Daimaruya T, Iikubo M, Kanzaki R, Takahashi I, Sugawara J,\& Sasano, T. (2007).Morphologic and hemodynamic analysis of dental pulp in dogs after molar intrusion with the skeletal anchorage system. Am J Orthod Dentofacial Orthop. 132: 199-207.

Kreisner PE, Blaya DS, Gaião L, Maciel-Santos ME, Etges A, Santana-Filho M, de Oliveira MG. (2010).Histological evaluation of the effect of low-level laser on distraction osteogenesis in rabbit mandibles. Med Oral Patol Oral Cir Bucal.2010 Jul 1;15(4):e6168.

Krishnan V, Kumar K J. 2004 Weld characteristics of orthodontic archwire materials. Angle Orthodontist $74: 533-538$

Kronenberg O, A. Lussi, and S. Ruf, "Preventive effect of ozone on the development of white spot lesions during multibracket appliance therapy," Angle Orthodontist, vol. 79, no. 1, pp. 64-69, 2009.

Kudoh, C., Inomata, K., Okayami, K., Motegi, M.,Ohshiro T. (1989). Low Level Laser Therapy Pain Attention Mechanisms. Laser Therapy ,1(1), 3-6.

Lalani N, Foley TF, Voth R, Banting D, Mamandras A. Polymerization with the argon laser: curing time and shear bond strength. Angle Orthod 2000;70:28-33.

Lee BS, Hsieh TT, Lee YL, Lan WH, Hsu YJ, Wen PH, Lin CP (2003) Bond strength of orthodontic bracket after acid-etched, Er:YAG laser-irradiated and combined treatment on enamel surface. Angle Orthod 73:565-570

Lenz P, Glide H, Walz R. Studies on enamel sealing with the CO2 laser. Dtsch Zahnarztl Z 1982;37: 469-78.

Li R, Ren Y, Han J (2000) Effects of pulsed Nd:YAG laser irradiation on shear bond strength of composite resin bonded to porcelain. Hua Xi Kou Qiang Yi Xue Za Zhi 18:377379

LI, Lu P, Zhongke Wang Y, Chen J, Zhao J. The research and development of noncontact 3-D laser dental model measuring and analyzing system. Chinese Journal of Dental Research 2000;3:7-14.

Lim HM, Lew KKK, Tay DKL. A clinical investigation of the efficacy of low level laser therapy in reducing orthodontic post adjustment pain. Am J Orthod Dentofacial Orthop 1995;108:614-22.

Limpanichkul W, Godfrey K, Srisuk N, Rattanayatikul C (2006) Effects of low-level laser therapy on the rate of orthodontic tooth movement. Orthod Craniofac Res 9:38-43

Limpanichkul W, Godfrey K, Srisuk N, Rattanayatikul C. Effects of low-level laser therapy on the rate of orthodontic tooth movement. Orthod Craniofac Res. 2006; 9: 38-43.

Lioubavina-Hack N. Lasers in dentistry. 5. The use of lasers in periodontology. Ned Tijdschr Tandheelkd. 2002;109:286-292.

Lioubavina-Hack N. Lasers in dentistry. 5. The use of lasers in periodontology. Ned Tijdschr Tandheelkd. 2002;109:286-292.

Liu, J. , Watanabe, I., Yoshida, K ,\& Atsuta M.( 2002). Joint strength of laser-welded titanium . Dental Materials $18: 143-148$ 
Lovrov, S., Hertrich, K., Hirschfelder U. (2007). Enamel Demineralization during Fixed Orthodontic Treatment - Incidence and Correlation to Various Oral-hygiene Parameters. J Orofac Orthop ,68(5): 353-363.

Lussi, A., E. Hellwig, "Performance of a new laser fluorescence device for the detection of occlusal caries in vitro," Journal of Dentistry, vol. 34, no. 7, pp. 467-471, 2006.

Lussi A, Hack A, Hug I, Heckenberger H, Megert B, Stich H (2006) Detection of approximal caries with a new laser fluorescence device. Caries Res 40:97-103

Lussi A, R. Hibst, \& Paulus,R. (2004).DIAGNOdent: an optical method for caries detection, Journal of Dental Research, vol. 83, supplement 1, pp. C80-C83

Maijer, R., Smith DC. (1979). A new surface treatment for bonding. J Biomed Mater Res ,13(6): 975-985.

Maiman, TH.(1960). Stimulated optical radiation in ruby masers. Nature 187: 493-494.

Marcusson, A., Norevall LI, Persson M. (1997). White spot reduction when using glass ionomer cement for bonding in orthodontics: a longitudinal and comparative study. Eur J Orthod ,19(3): 233-242.

Ma, T., Marangoni., RD,\& Flint W .(1997) .In vitro comparison of debonding force and intrapulpal temperature changes during ceramic orthodontic bracket removal using carbon dioxide laser. Am J Orthod Dentofacial Orthop,111:203-210

Marmulla, R., Hassfeld S, Luth, T,\& Muhling, J. (2003).Laser-scan-based navigation in cranio-maxillofacial surgery. J Craniomaxillofac Surg , 31: 267-77.

Martinez-Insua, A., Da Silva, Dominguez, L., Rivera FG, Santana-Penin UA. 2000. Differences in bonding to acid-etched or Er:YAG-laser-treated enamel and dentin surfaces. J Prosthet Dent ,84(3): 280-288.

Mattson, J. S., Blankenau. R., Keene, J.J. (1998) Use of an argon laser to treat drug-induced gingival over growth. JADA, 129, 78-89.

McCance AM, J.P. Moss, W.R. Fright, A.D. Linney and D.R. James, Three-dimensional analysis techniques - Part 1: three-dimensional soft-tissue analysis of 24 adult cleft palate patients following Le Fort I maxillary advancement: a preliminary report, Cleft Palate Craniofac J 34 (1997): 36-45.

McCance, AM., Moss, JP. W.R. Wright, A.D. Linney \& James, DR. (1992). A threedimensional soft tissue analysis of 16 skeletal Class III patients following bimaxillary surgery. Br J Oral Maxillofac Surg ,30: 221-232.

McDonagh S., J.P. Moss, P. Goodwin and R.T. Lee, .(2001). A prospective optical surface scanning and cephalometric assessment of the effect of functional appliances on the soft tissues, Eur J Orthod ,23: 115-126.

McCartney ,JW.,\& Doud R.(1993).Passive adaptation of the prosthesis-implant interface by soldering gold cylinders to the framework casting. Journal of Prosthetic Dentistry, 70:17-20.

McDonald F, Pitt Ford TR. (1994).Blood flow changes in permanent maxillary canines during retraction. Eur J Orthod,16: 1-9.

McGuinness, NJ., Stephens CD. (1992). Storage of orthodontic study models in hospital units in the U.K. British Journal of Orthodontics, 19:227-232.

Meister, J.(2007).Basic Research, In: Proceedings of the $1^{\text {st }}$ International Workshop of Evidence Based Dentistry on Lasers in Dentistry, Gutknecht N, pp.( 3-27), Quintessence publisher,ISBN:978-1-85097-167-2,Berlin 
Merberg G N.(1993). Current status of infrared fiber optics for medical laser power delivery. Lasers Surg Med , 13: 572-576.

Meserendino, LJ., Pick ,RM. (1995), Lasers in Dentistry, Chicago, Ill: Quintessence

Mester,E., Szende, B. \& Gartner,P.(1968). The effect of laser beams on the growth of hair in mice, Radiobiol Radiother (Berl) $921-6$. Moulton, P. F. (1982) Ti-doped sapphire tunable solid state lasers. Optics News 8,9.

Mills, RW. (19950. Blue light emitting diodes--another method of light curing? Br Dent J ,178(5): 169.

Miloro M, Miller JJ, Stoner JA.(2007). Low-level laser effect on mandibular distraction osteogenesis.J Oral Maxillofac Surg.Feb;65(2):168-76.

Mimura, H., Deguchi, T., Obata, A., Yamagishi T, Ito M (1995) Comparison of different bonding materials for laser debonding. Am J Orthod Dentofacial Orthop ,108:267-273

Mizutani, K., Musha, Y., Tobe, M. (2002). Clinical study on prostaglandin E2 with diode laser therapy. Proc. 4th Congr World Assoc for Laser Therapy,. Tsukuba, Japan, 82.

Moritz, A. (2006).Oral Laser Application. Chicago, Ill: Quintessence.

Moslemi, M., Fekrazad, R., Tadayon, N., Ghorbani, M., Torabzadeh, H.,\& Shadkar, MM. (2009) .Effects of ER,Cr:YSGG laser irradiation and fluoride treatment on acid resistance of the enamel. Pediatr Dent, Sep-Oct;31(5):409-13.

Moss, JP., Grindrod, SR., Linney AD, Arridge SR,\& James D. (1988).A computer system for the interactive planning and prediction of maxillofacial surgery. Am J Orthod Dentofacial Orthop, Dec; 94(6): 469-75.

Moss, JP., Linney, AD., Grindrod SR, Arridge SR, Clifto,JS.(1987).Three-dimensional visualization of the face and skull using computerized tomography and laser scanning techniques. Eur J Orthod,Nov;9(4):247-53.

Moss JP, S.F. Ismail and R.J. Hennessy, (2003). Three-dimensional assessment of treatment outcomes on the face, Orthod Craniofac Res 6 (Suppl 1), pp. 126-131; 179-82.

Myers, TD., Myers, WD., \& Stone, RM. (1989).First soft tissue study utilising a pulsed Nd YAG dental laser. Northwest Dent; 68: 14-17

Nalbantgil D, Oztoprak MO, Tozlu M, Arun T (2010). Effects of different application durations of ER:YAG laser on intrapulpal temperature change during debonding. Lasers Med Sci,

Nathan, M. 1., Dumke, W. P., Burns, G., Dill Jr., F. H., Lasher, G. (1962) Stimulated emission of radiation from GaAs p-n junctions. Appl Phys Lett ,1(3), 62-64.

Niemz, MH. ( 2002) Laser-Tissue Interactions: Fundamentals and Applications. Berlin, Germany: Springer Verlag: 45-80.

Nelson, DG., Shariati M, Glena R, Shields CP, Featherstone JD. (1986).Effect of pulsed low energy infrared laser irradiation on artificial caries-like lesion formation. Caries Res , 20:289-99.

Nelson, DG., Wefel JS, Jongebloed WL, Featherstone JD.(1987). Morphology, histology, and crystallography of human dental enamel treated with pulsed low-energy infrared laser radiation. Caries Res,21:411-26.

Nute SJ, Moss JP. (2000). Three-dimensional facial facial growth studied by optical surface scanning.J Orthod, 27: 31-38.

Obata A, Tsumura T, Niwa K, Ashizawa Y, Deguchi T, Ito, M .(1999) .Super pulse CO2 laser for bracket bonding and debonding. Eur J Orthod, 21:193-198 
O'brien, WJ. (1997). Dental materials and their selection. 2nd ed. Chicago: Quintescence Publishing Co: 308,309.

Odegaard J, Segner D. 1988. Shear bond strength of metal brackets compared with a new ceramic bracket. Am J Orthod Dentofacial Orthop 94(3): 201-206.

Tocchio RM, Williams PT, Mayer FJ, Standing KG. 1993. Laser debonding of ceramic orthodontic brackets. Am J Orthod Dentofacial Orthop 103(2): 155-162.

Odor TM, Pitt Ford TR, McDonald F. Effect of wavelength and bandwidth on the clinical reliability of laser Doppler recordings. Endod Dent Traumatol 1996;12:9-15.

Oho T, Morioka T. A possible mechanism of acquired acid resistance of human dental enamel by laser irradiation. Caries Res 1990;24:86-92.

Olivi G, Chaumanet G, Genovese MD, Beneduce C, Andreana S.(2010). Er,Cr:YSGG laser labial frenectomy: a clinical retrospective evaluation of 156 consecutive cases. Gen Dent. May-Jun;58(3):e126-33.

Ogaard B, Rolla G, Arends J. (1988)a. Orthodontic appliances and enamel demineralization. Part 1. Lesion development. Am J Orthod Dentofacial Orthop 94(1): 68-73.

Ogaard B, Rolla G, Arends J, ten Cate JM. (1988)b. Orthodontic appliances and enamel demineralization. Part 2. Prevention and treatment of lesions. Am J Orthod Dentofacial Orthop, 94(2): 123-128.

Orthod Dentofacial Orthop 128(5):630-637

Ozer, T., Başaran G, Berk N.(2008). Laser etching of enamel for orthodontic bonding. Am J Orthod Dentofacial Orthop. Aug;134(2):193-7.

Oztoprak MO, Nalbantgil D, Erdem S, Tozlu M, Arun T. (2010) .Debonding of ceramic brackets by a new scanning laser method. Am J Orthod Dentofacial Orthop, Aug;138(2):195-200.

Paghdiwala, A. F. (1988) Application of the erbim: YAG laser on hard dental tissues: measurement of the termperature changes and depth of cut. In: Laser research in medicine, surgery and dentistry, ed. Profio, A. E., ICA-LEO '88. Vol. 64, 192-201.

Parker, s.(2007) .Verifiable CPD paper: introduction, history of lasers and laser light production, Br Dent J , January 202, 21 - 31

Patel, C. K. N. (1964 a) Continuos-wave laser action on vibrational - rotational transitions of CO2. Phys Rev Lett,136(5A), A1187-A1193.

Patel, C.K. N. (1964 b) Interpretation of CO2 optical maser experiments. Phys Rev Lett ,12(21), 588-590.

Polat, O., Karaman, AI.,\& Durmus, E. (2005). Effects of preoperative ibuprofen and naproxen sodium on orthodontic pain. Angle Orthod ,75(5): 791-796.

Poosti, M., Jahanbin, A., Mahdavi, P., Mehrnoush, S. (2011).Porcelain conditioning with Nd:YAG and Er:YAG laser for bracket bonding in orthodontics. Lasers Med Sci, Jan 18.

Powell, GL., Anderson, JR.,\& Blankenau, RJ. Laser and curing light induced in vitro pulpal temperature changes. J Clin Laser Med Surg 1999;17:3-5.

Powell, G.L., Ellis, R., Blankenau, R. J., Schouten, J.R. (1995). Evaluation of argon laser and conventional light cured composites. J Clin Laser Med Surg ,13(5), 315- 317.

Proffit, WR., Fields, HW.,\& Sarver, DM .(2007). Contemporary orthodontics. $4^{\text {th }}$ ed. St. Louis: Mosby: 335

Qiao, LY., Yu JT.,\& Jia XY. (2005).A study on acquired acid resistance of enamel and dentin irradiated by Er,Cr:YSGG laser in vitro. Zhonghua Kou Qiang Yi Xue Za Zhi ,40:34-7 
Quimby, ML., Vig, KWL., Rashid, RG.,\& Firestone, AR. (2004). The accuracy and reliability of measurements made on computer-based digital models. Angle Orthodontist ,74:298-303.

Quist, T.M., Rediker, R.H., Keyes, R. J., Krag, W. E., Lax, B., McWhorter, A. L., Zeigler, H. J. (1962) Semiconductor master of GaAs. App Phys Lett ,1(4), 91-92.

Reis, A., F. M. Mendes, V. Angnes, G. Angnes, R. Grande, HM., \& Loguercio, AD.(2006). Performance of methods of occlusal caries detection in permanent teeth under clinical and laboratory conditions. Journal of Dentistry, vol. 34, no. 2, pp. 89-96

Rickabaugh, JL., Marangoni, RD., McCaffrey KK (1996).Ceramic bracket debonding with the carbon dioxide laser. Am J Orthod Dentofacial Orthop , 110:388-393

Rocha,R., Ardenghi,TM., Oliveira,LB., Rodrigues,CRMD., \& Ciamponi,AL. (2003).In vivo effectiveness of laser fluorescence compared to visual Inspection and radiography for the detection of occlusal caries in primary teeth. Caries Research, vol. 37, no. 6, pp. 437-441

Rocha, R., Pinheiro, AL., \&Villaverde AB.(2006) Flexural strength of pure Ti, Ni-Cr and Co$\mathrm{Cr}$ alloys submitted to Nd:YAG laser or TIG welding. Brazilian Dental Journal, 17:20-23.

Roelandts, R.(2002).The history of phototherapy: something new under the sun, J Am Acad Dermatol, 46 :926-30.

Rose, RK. (2000)a. Binding characteristics of Streptococcus mutans for calcium and casein phosphopeptide. Caries Res ,34(5): 427-431.

Rose, RK. 2000b. Effects of an anticariogenic casein phosphopeptide on calcium diffusion in streptococcal model dental plaques. Arch Oral Biol, 45(7): 569-575.

Rossman, JA., \& Cobb, CM. (1995).Lasers in periodontal therapy. Periodontol 2000 , oct; 9, pp. 150-164.

Rueggeberg, FA., Caughman, WF., Curtis, JW. (1994). Effect of light intensity and exposure duration on cure of resin composite. Oper Dent ,19(1): 26-32.

Saito, S., \& Shimizu ,N .(1997). Stimulatory effects of low-power laser irradiation on bone regeneration in midpalatal suture during expansion in the rat. Am J Orthod Dentofacial Orthop , 111(5):525-532

Sano, Y., Ikawa, M., Sugawara, J., Horiuchi, H., \&Mitani, H. (2002). The effect of continuous intrusive force on human pulpal blood flow. Eur J Orthod,24:159-166.

Santoro, M., Galkin ,S., Teredesai, M., Nicolay ,OF.,\& Cangialosi TJ.(2003). Comparison of measurements made on digital and plaster models. American Journal of Orthodontics and Dentofacial Orthopedics ,124:101-105.

Saperia, D., Glassberg, E., Lyons, R. F., Abergel. R. P., Baneux, P., Castel, J. C., Dwyer, R.M., Uitto, J. (1986) Demonstration of elevated type I and type III procollagen m RNA levels in cutaneous wounds treated with helium - neon laser. Biochem Biophys Res Commun ,3 (138), 1123- 1128.

Sarver, DM.(2006). Use of the $810 \mathrm{~nm}$ diode laser: soft tissue management and orthodontic applications of innovative technology. Practice Proced Aesthet Dent ,18 (suppl), pp. 7-13.

Sarver, DM.,\& Yanosky M.(2005). Principles of cosmetic dentistry in orthodontics: part 2. Soft tissue laser technology and cosmetic gingival contouring. Am J Orthod Dentofacial Orthop, 127:85-90. 
Sasano, T. (1998). Neural regulation of pulpal blood flow and pulp diagnosis. Tohoku Univ Dent J, 17:1-21.

Schawlow, AL. ,Townes, CH.(1940,1949,1958).Infrared and Optical Masers . Phys, Rev 112.

Seifi, M., Shafeei, HA., Daneshdoost, S. (2007). Effects of two types of low-level laser wave lengths $(850$ and $630 \mathrm{~nm})$ on the orthodontic tooth movements in rabbits. Lasers Med Sci ,22:261-264

Sergl, HG., Klages, U.,\& Zentner A. (1998). Pain and discomfort during orthodontic treatment: causative factors and effects on compliance. Am J Orthod Dentofacial Orthop ,114(6): 684-691.

Sestini, S., Notarantonio, L., Cerboni B, Alessandrini C, Fimiani M, Nannelli P, Pelagalli A, \& Giorgetti, R.(2006). In vitro toxicity evaluation of silver soldering, electrical resistance, and laser welding of orthodontic wires. Eur J Orthod. Dec;28(6):567-72.

Sholts, SB., Wa"rmla“nder SKTS., Flores,LM., Miller,KWP., Walker, PL. (2010). Variation in the measurements of cranial volume and surface area using $3 \mathrm{D}$ laser scanning technology. J. Forensic Sci,(April 8) (Epub ahead of print).

Silta, YT., Dunn, WJ,\& Peters, CB.( 2005). Effect of shorter polymerization times when using the latest generation of light-emitting diodes. Am J Orthod Dentofacial Orthop ,128(6): 744-748.

Skold-Larsson K., Fornell,AC., Lussi,A. \& Twetman,S. (2004).Effect of topical applications of a chlorhexidine/thymol-containing varnish on fissure caries assessed by laser fluorescence," Acta Odontologica Scandinavica, vol. 62, no. 6, pp. 339-342

Sognnaes, RF., \& Stern, RH. (1965). Laser effect on resistance of human dental enamel to demineralization in-vitro. J S Calif Dent Assoc ,33: 328-329.

Solmi, R. „Martini, D., Zanarini, M., Isaza Penco S, Rimondini, L., Carinci, P., Borea, G.,\& Ruggeri ,A.. (2004). Interactions of fibroblasts with soldered and laser welded joints. Biomaterials, 25: 735-740

Srimaneepong, V., Yoneyama, T., Kobayashi, E., Doi, H., Hanawa,T. (2005). Mechanical strength and microstructure of laser-welded Ti-6Al-7Nb alloy castings . Dental Materials Journal ,24: 541 - 549

Staudt ,CB., Lussi, A., Jacquet, J., \& Kiliaridis, S. (2004).White spot lesions around brackets: in vitro detection by laser fluorescence. Eur J Oral Sci,112:237-243

Strobl, K., Bahns, TL., Willham, L., Bishara SE, Stwalley WC .(1992). Laser-aided debonding of orthodontic ceramic brackets. Am J Orthod Dentofacial Orthop ,101:152-158

Sun, X., Zhu, X., Xu, C., Ye, N.,\& Zhu, H .(2001). Effects of low energy laser on tooth movement and remodeling of alveolar bone in rabbits. Hua Xi Kou Qiang Yi Xue Za Zhi 19(5):290-293

Talbot, TQ., Blankenau RJ, Zobitz, ME., Weaver, AL., Lohse, CM., \& Rebellato J.(2000). Effect of argon laser irradiation on shear bond strength of orthodontic brackets: an in vitro study. Am J Orthod Dentofacial Orthop, 118:274-9.

Taylor JC. , Hondrum SO. , Prasad, A. , Brodersen, CA. (1998). Effects of joint configuration for the arc welding of cast Ti-6Al-4V alloy rods in argon. Journal of Prosthetic Dentistry $79: 291$ - 297

Tehranchi, A., Fekrazad, R., Zafar, M., Eslami, B., Kalhori, KA., \& Gutknecht, N. (2010). Evaluation of the effects of $\mathrm{CO} 2$ laser on debonding of orthodontics porcelain brackets vs. the conventional method. Lasers Med Sci, Aug 20. [Epub ahead of print] 
Theodorakopoulou, LP., Sadowsky, PL., Jacobson, A., Lacefield W, Jr. 2004. Evaluation of the debonding characteristics of 2 ceramic brackets: an in vitro study. Am J Orthod Dentofacial Orthop ,125(3): 329-336.

Thilander, B., Rygh, P., \& Reitan K. Tissue reactions in orthodontics. In: Graber TM, Vanarsdall RL, Vig KWL. Orthodontics: Current principles \& techniques. $4^{\text {th }}$ ed. St. Louis: Mosby: 168,169.

Turhani, D., Scheriau M, Kapral D, Benesch T, Jonke E,\& Bantleon, HP. (2006). Pain relief by single low-level laser irradiation in orthodontic patients undergoing fixed appliance therapy. Am J Orthod Dentofacial Orthop ,130(3): 371-377.

Tocchio, RM., Williams, PT., Mayer, FS, \& Standing KG. (1993). Laser debonding of ceramic orthodontic brackets. Am J Orthod Dentofacial Orthop, 103:155-162

Tortamano, A., Lenzi, DC., Haddad, AC., Bottino, MC., Dominguez, GC., Vigorito, JW.(2009). Low-level laser therapy for pain caused by placement of the first orthodontic archwire: a randomized clinical trial. Am J Orthod Dentofacial Orthop, 136: 662-667.

Townes, CH.( 1994). Making waves. New York: Springer-Verlag,

Tranaeus, S., Lindgren,LE., Karlsson, L.\& Angmar-Mansson,B. (2004).In vivo validity and reliability of IR fluorescence measurements for caries detection and quantification. Swedish Dental Journal, vol. 28, no. 4, pp. 173-182

Tronstad, L.(1992). Recent development in endodontic research. Scand J Dent Res ,100:52-9.

Tufekci, E., Dixon, JS., Gunsolley, JC., Lindauer SJ. 2011. Prevalence of white spot lesions during orthodontic treatment with fixed appliances. Angle Orthod 81(2): 206-210.

Turhani, D., Scheriau, M., Kapral, D., Benesch, T., Jonke E, \&Bantleon, HP.(2006). Pain relief by single low-level laser irradiation in orthodontic patients undergoing fixed appliance therapy. Am J Orthod Dentofacial Orthop,130: 371-377.

Usumez, S., Buyukyilmaz, T.,\& Karaman, AI. (2003). Effects of fast halogen and plasma arc curing lights on the surface hardness of orthodontic adhesives for lingual retainers. Am J Orthod Dentofacial Orthop ,123(6): 641-648.

Usümez, S., Orhan, M., Usümez, A. (2002).Laser etching of enamel for direct bonding with an Er,Cr:YSGG hydrokinetic laser system. Am J Orthod Dentofacial Orthop;122:64956.

Vanarsdall, RL.,\& Secchi, AG. Periodontal orthodontic interrelationships. In: Graber TM, Vanarsdall RL, Vig KWL. Orthodontics: Current principles \& techniques. $4^{\text {th }}$ ed. St. Louis: Mosby: 919.

Van Noort, R. (2002). Introduction to dental materials. 2nd ed. Edinburgh: Mosby: 284

Visuri, SR., Gilbert, JL., Wright, DD., Wigdor ,HA., Walsh, JT Jr. Shear strength of composite bonded to Er:YAG laser-prepared dentin. J Dent Res 1996;75:599-605.

Vongsavan N, Matthews B. Some aspects of the use of laser Doppler flow meters for recording tissue blood flow. Exp Physiol 1993;78:1-14.

Vukovich ,ME., Wood, DP.,\& Daley ,TD.( 1991). Heat generated by grinding during removal of ceramic brackets. Am J Orthod Dentofacial Orthop ,99(6): 505-512.

Walsh LJ, Goharkhay K, Verheyen P, Moritz A.(2006).Low Level Laser Therapy, In: Oral Laser Application, Mortiz A, PP.(521-539),Quintessenz Publisher,ISBN:1-85097-1501,Berlin,Germany 
Watanabe I , Baba N , Chang J , Chiu Y 2006 Nd:YAG laser penetration into cast titanium and gold alloy with different surface preparations . Journal of Oral Rehabilitation, 33 : $443-446$

Watanabe, I., Liu, J.,\& Atsuta, M.(2001). Effects of heat treatments on mechanical strength of laser-welded equi-atomic AuCu-6at\%Ga alloy. Journal of Dental Research ,80:18131817.

Watanabe, I., Liu, J., Atsuta M, Okabe T.(2003). Effect of welding method on joint strength of laser-welded gold alloy. American Journal of Dentistry , 16:231-234.

Watanabe, I., Liu, J., Baba N, Atsuta M,\& Okabe T. (2004).Optimizing mechanical properties of laser-welded gold alloy through heat treatment. Dental Materials, 20:630-634.

Watanabe I , Topham D S (2004) Tensile strength and elongation of laserwelded Ti and Ti6AL-7NB . Journal of Biomedical Materials Research Part B, Applied Biomaterials 71 : 46 $-51$

Watanabe, I. ,\& Topham, DS.( 2006). Laser welding of cast titanium and dental alloys using argon shielding. Journal of Prosthodontics, $15: 102-107$

Wendl, B., \& Droschl, H. (2004). A comparative in vitro study of the strength of directly bonded brackets using different curing techniques. Eur J Orthod ,26(5): 535-544.

Wigdor, H., Abt ,E., Ashrafi, S.,\& Walsh, JT . (1993). The effect of lasers on dental hard tissues. J Am Dent Assoc, 124(2):65-70

Wigdor, HA., Walsh, JT., Featherstone, JDB., Visuri, SR., Fried, D., \&Waldvogel JL. (1995).Lasers in dentistry. Laser Surg Med ,16:103-33.

Xianglong ,H., Xiaolin, L., Ding, B., Yao, M., \&Lan, H. (2008) Nd: YAG laser-aided ceramic brackets debonding: effects on shear bond strength and enamel surface. Appl Surf Sci , 255(2):613-615

Xiaoting, L., Yin, T., \& Yangxi, C.(2010). Interventions for pain during fixed orthodontic appliance therapy. Angle Orthodontist, 80: 925-32.

Yamada, T., Mori, Y., Katsuhiro, M., Katsuaki, M., \&Tsukamoto Y. (2002).Three-dimensional analysis of facial morphology in normal Japanese children as control data for cleft surgery, Cleft Palate.Craniofac J ,39: 517-526.

Yamagishi, T., Ito, M.,\&Fujimura, Y.,(1993) Mechanical properties of laser welds of titanium in dentistry by pulsed Nd:YAG laser apparatus . Journal of Prosthetic Dentistry ,70 : $264-273$

Yamaguchi, M. (2007). Low-energy laser irradiation stimulates the tooth movement velocity via expression of M-CSF and c-fms. Orthodontic Waves 66: 139-148

Yamaguchi, M., Hayashi ,M., Fujita, S., Yoshida, T., Utsunomiya ,T., Yamamoto, H., \&Kasai, K. (2010). Low-energy laser irradiation facilitates the velocity of tooth movement and the expressions of matrix metalloproteinase-9, cathepsin $\mathrm{K}$, and alpha(v) beta(3) integrin in rats.European J Orthodont ,32(2): 131-139.

Yamamoto, HY., \&Sato, K.(1980). Prevention of dental caries by Nd:YAG laser irradiation. J Dent Res , 59: 2171-2177.

Yan, XJ., Yang, DZ.(2006). Corrosion resistance of a laser spot-welded joint of NiTi wire in simulated human body fluids. Journal of Biomedical Materials Research Part A, 77:97102.

Yao, CC., Lee ,JJ., Chen, HY., Chang, ZC., Chang ,HF.,\& Chen YJ.(2005). Maxillary molar intrusion with fixed appliances and miniimplant anchorage studied in three dimensions. Angle Orthod, 75:754-760. 
Yoshida, S., Kazuhiko, O., \& Kazuo, T. (1996).Biological responses of the pulp to singletooth dento-osseous osteotomy. Oral Surg Oral Med Oral Pathol Oral Radiol Endod, 82: 152-160.

Yoshida, T., Yamaguchi, M., Utsunomiya, T., Kato, M., Arai, Y., Kaneda ,T., Yamamoto, H., \&Kasai, K. (2009) .Low-energy laser irradiation accelerates the velocity of tooth movement via stimulation of the alveolar bone remodeling. Orthod Craniofac Res ,12(4):289-298

Youssef, M., Ashkar,S., Hamade, E., Gutknecht, N., Lampert, F.,\& Mir, M. (2008) .The effect of low-level laser therapy during orthodontic movement: a preliminary study. Lasers Med Sci 23(1):27-33

Young, AN., Taylor, RW., Taylor SE, Linnebur SA,\& Buschang PH.( 2006). Evaluation of preemptive valdecoxib therapy on initial archwire placement discomfort in adults. Angle Orthod ,76(2): 251-259.

Zachrisson, BU., Buyukyilmaz, T .(2005). Bonding in orthodontics. In: Graber TM, Vanarsdall RL, Vig KWL. Orthodontics: Current principles $\mathcal{E}$ techniques, $4^{\text {th }}$ ed. St. Louis: Mosby: 596-600.

Zang, DY., Millerd ,JE., Wilder-Smith, PB., Arrastia, AM.(1996). A novel laser Doppler flowmeter for pulpal blood flow measurements. Proceedings of the International Society for Optical Engineering , 2672:21-6.

Zharikov, E. V., Osiko, V. V., Prokhorov. A. M., Scherbakov, I. A. (1984) Crystals of rare earth gallium garnets with chromium as active media for solid - state lasers . Inorg Aat , 48, 81-94.

Zharikov, E.V.,Zhekov, V. I., Kulevskii, L. A., Murina, T. M., Oslko, V.V., Prokhorov, A. M., Savel'ev , A. D., Smirnov, V.V., Starikov, B.P., Timoshechkin, M.I. (1975) Stimulated emission from Er3- ions in yttrium aluminium garnet crystals at $\lambda=2.94 \mu \mathrm{m}$. Sov J Quant Electron ,4(8), 1039-1040.

Zupancic, R., Legat, A., \& Funduk, N.(2006). Tensile strength and corrosion resistance of brazed and laser-welded cobalt-chromium alloy joints. Journal of Prosthetic Dentistry ,96:273-282. 


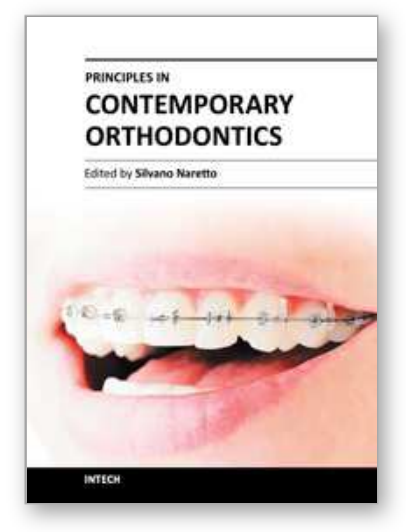

\author{
Principles in Contemporary Orthodontics \\ Edited by Dr. Silvano Naretto
}

ISBN 978-953-307-687-4

Hard cover, 584 pages

Publisher InTech

Published online 25, November, 2011

Published in print edition November, 2011

Orthodontics is a fast developing science as well as the field of medicine in general. The attempt of this book is to propose new possibilities and new ways of thinking about Orthodontics beside the ones presented in established and outstanding publications available elsewhere. Some of the presented chapters transmit basic information, other clinical experiences and further offer even a window to the future. In the hands of the reader this book could provide an useful tool for the exploration of the application of information, knowledge and belief to some orthodontic topics and questions.

\title{
How to reference
}

In order to correctly reference this scholarly work, feel free to copy and paste the following:

Fekrazad Reza, Kalhori A.M. Katayoun, Ahrari Farzaneh and Tadayon Nikoo (2011). Laser in Orthodontics, Principles in Contemporary Orthodontics, Dr. Silvano Naretto (Ed.), ISBN: 978-953-307-687-4, InTech, Available from: http://www.intechopen.com/books/principles-in-contemporary-orthodontics/laser-inorthodontics

\section{INTECH}

open science | open minds

\section{InTech Europe}

University Campus STeP Ri

Slavka Krautzeka 83/A

51000 Rijeka, Croatia

Phone: +385 (51) 770447

Fax: +385 (51) 686166

www.intechopen.com

\section{InTech China}

Unit 405, Office Block, Hotel Equatorial Shanghai

No.65, Yan An Road (West), Shanghai, 200040, China

中国上海市延安西路65号上海国际贵都大饭店办公楼405单元

Phone: +86-21-62489820

Fax: $+86-21-62489821$ 
(C) 2011 The Author(s). Licensee IntechOpen. This is an open access article distributed under the terms of the Creative Commons Attribution 3.0 License, which permits unrestricted use, distribution, and reproduction in any medium, provided the original work is properly cited. 